\title{
Article \\ A Comparative Study on Fault Detection Methods for Gas Turbine Combustion Systems
}

\author{
Jinfu Liu *, Zhenhua Long, Mingliang Bai ( ${ }^{\circ}$, Linhai Zhu and Daren Yu \\ Harbin Institute of Technology, Harbin 150001, China; zhenhualong@hit.edu.cn (Z.L.); \\ mingliangbai@outlook.com (M.B.); zhulinhaihit@outlook.com (L.Z.); yudaren@hit.edu.cn (D.Y.) \\ * Correspondence: jinfuliu@hit.edu.cn
}

check for updates

Citation: Liu, J.; Long, Z.; Bai, M.; Zhu, L.; Yu, D. A Comparative Study on Fault Detection Methods for Gas Turbine Combustion Systems. Energies 2021, 14, 389. https:// doi.org/10.3390/en14020389

Received: 14 November 2020 Accepted: 8 January 2021 Published: 12 January 2021

Publisher's Note: MDPI stays neutral with regard to jurisdictional clai$\mathrm{ms}$ in published maps and institutional affiliations.

Copyright: (C) 2021 by the authors. Licensee MDPI, Basel, Switzerland. This article is an open access article distributed under the terms and conditions of the Creative Commons Attribution (CC BY) license (https:// creativecommons.org/licenses/by/ $4.0 /)$.

\begin{abstract}
As one of the core components of gas turbines, the combustion system operates in a high-temperature and high-pressure adverse environment, which makes it extremely prone to faults and catastrophic accidents. Therefore, it is necessary to monitor the combustion system to detect in a timely way whether its performance has deteriorated, to improve the safety and economy of gas turbine operation. However, the combustor outlet temperature is so high that conventional sensors cannot work in such a harsh environment for a long time. In practical application, temperature thermocouples distributed at the turbine outlet are used to monitor the exhaust gas temperature (EGT) to indirectly monitor the performance of the combustion system, but, the EGT is not only affected by faults but also influenced by many interference factors, such as ambient conditions, operating conditions, rotation and mixing of uneven hot gas, performance degradation of compressor, etc., which will reduce the sensitivity and reliability of fault detection. For this reason, many scholars have devoted themselves to the research of combustion system fault detection and proposed many excellent methods. However, few studies have compared these methods. This paper will introduce the main methods of combustion system fault detection and select current mainstream methods for analysis. And a circumferential temperature distribution model of gas turbine is established to simulate the EGT profile when a fault is coupled with interference factors, then use the simulation data to compare the detection results of selected methods. Besides, the comparison results are verified by the actual operation data of a gas turbine. Finally, through comparative research and mechanism analysis, the study points out a more suitable method for gas turbine combustion system fault detection and proposes possible development directions.
\end{abstract}

Keywords: gas turbine model; combustion system; fault detection; comparative study

\section{Introduction}

In the process of gas turbine development, with the improvement of its efficiency, the combustor outlet temperature is getting higher and higher [1]. The adverse working environment leads to a high incidence of combustion system faults. In addition, it is very expensive, and once it suffers a fault and is damaged, it may also pose a serious threat to the safety of downstream nozzles and blades, causing huge losses [2]. For instance, through visual analysis following the failure and numerical simulations of a second rotor stage in heavy-duty gas turbine, Sawiński et al. [3] found that the increase in combustion temperature, which may be caused by combustion system faults, would greatly increase the probability of turbine failure. Implementation of prognostics and health management (PHM) can help gas turbines run safely and economically by improving their reliability, safety, and availability, while reducing the operational costs [4,5]. Anomaly detection plays an important role in PHM systems, which can detect performance degradation immediately and clear faults before they have fully developed. Therefore, the early fault detection of gas turbine combustion systems is particularly important.

The combustor of gas turbines is generally of an annular or ring tube type. The fuel enters the combustor through a number of fuel nozzles for combustion. Each combustor has 
the same structure and is evenly arranged along the circumferential direction. Ideally, the temperature at the outlet of each combustor is basically identical, and when a combustor fails, it will affect the temperature of the gas in it and cause fluctuations at its outlet temperature [6]. However, the temperature at the exit of combustor varies from 1300 to $1700{ }^{\circ} \mathrm{C}$, depending on the power of the gas turbine [1] and conventional temperature sensors cannot work for a long time at such high temperatures, but the temperature fluctuation at the outlet of combustor will cause abnormal temperature of the corresponding gas path at the turbine outlet [7]. In practical applications, temperature measuring thermocouples placed at the turbine outlet are used to monitor the EGT distribution to indirectly monitor the performance of the combustion system. The thermocouples are arranged uniformly in the circumferential direction at the turbine outlet, so the measured EGT can reflect the status of the combustion system. Ideally, the temperature measured by each thermocouple should also be identical. In practice, due to manufacturing and installation errors and subtle differences in fuel supply, the values of each thermocouple are not exactly the same, although the difference is very small. When the wall of the combustor or a transition section cracks, deformation, ablation and carbon deposition, uneven fuel distribution, jet angle deflection occur [5], and this will cause the exit temperature of the faulty combustor to deviate from the temperature of other normal combustors, which is manifested as a local high temperature or a local low temperature in the circumferential direction. These local temperature anomalies will pass through the turbine to the thermocouples. If the reading of one or several adjacent thermocouples are significantly higher or lower than that of other thermocouples, it indicates that the combustor corresponding to the thermocouple is faulted, that is, we have a combustion system fault detection method based on the EGT distribution.

In addition to the method of using the EGT distribution to detect faults, there are also the methods of using fuel efficiency to measure the status of combustion system [8]; using endoscopes for non-destructive testing after shutdown [9] and methods based on electrostatic monitoring technology [10-14], etc. At present, the most widely used method is to monitor the EGT distribution for fault detection. It provides the most relevant information about the performance of combustion systems [15]. When the unit is operating normally, the EGT distribution is uniform; the more uneven the EGT distribution, the greater the probability of a malfunction of the combustion system.

However, the malfunction of the combustion system is not the only factor that can cause an uneven temperature distribution [16]. During the operation of a gas turbine, there are many interfering factors, including ambient conditions, operating conditions, component performance degradation, the manufacturing and installation errors of thermocouples, etc. The fluctuating and uneven signal of the EGT caused by a malfunction of the combustion system is very feeble. In the early stage of the combustion system fault, even if the combustor burns through and forms palm-sized damage, the resulting EGT change is only $5-10{ }^{\circ} \mathrm{C}$ [17]. Comparing with the EGT change caused by the combustion system fault, the change caused by these non-fault interference factors can easily submerge that caused by faults, so that the faults cannot be detected as soon as possible. At the same time, the hot gas will rotate with the turbine blades, and its swirl angle will change with the change of operating conditions. There is also a blending effect between the gas from different combustion chambers, which will reduce the unevenness of the EGT distribution. These interference factors will reduce the sensitivity and increase the difficulty of anomaly detection. In order to overcome these difficulties, researchers have carried out a large number of studies and proposed a series of methods for fault detection of combustion systems. These studies can be divided into two types, spread-based methods and model-based methods.

The spread-based methods use the EGT dispersion to detect faults. If the values of some thermocouples differ greatly from those of other thermocouples, it means that the combustion system is faulty $[18,19]$. As one of the most widely used monitor systems, the MARK VI system [20] produced by GE utilizes temperature differences between the maximum EGT and the three minimum EGTs. It defines a parameter, called allowable exhaust temperature dispersion, which is a function of the average EGT and the compressor 
outlet temperature. The higher the ratio of the temperature differences to the allowable exhaust temperature dispersion, the greater the possibility of a fault. The hot protection and cold protection of the TELEPERM XP system [21], produced by, utilizes the temperature deviation of a single thermocouple from the average EGT for warning, and uses the deviation to determine whether to perform other protection actions. The system introduced in [22], in addition to monitoring deviations, also monitors the changes in the maximum, median and average values of EGT. Gulen et al. [23] introduced a heavy-duty industrial gas turbine real-time online performance diagnostic system. In the system, excessive and sudden changes or consistent upward trends in the ratio of the maximum EGT to the average of EGT indicate the potential combustor faults. The spread-based method is very intuitive, so it has been widely used in industry.

The model-based methods use the EGT distribution model for fault detection, and they can be divided into two categories. The first type is the use of established gas turbine models, including physical models and data-driven models. After inputing the operation and other parameters, the established model outputs the estimated exhaust temperature. When the gas turbine is normal, the estimated value is basically the same as the actual value and the residual error is small; when the residual error exceeds the threshold, it indicates that a fault has occurred. The physical models are established using prior physical knowledge of the gas turbine. Basseville et al. [24,25] established a physical model of EGT and calculated the gas swirl angle based on the principle of gas turbine. Korczewski et al. [26] established an EGT model based on the thermodynamic and gas flow process of a gas turbine. Medina et al. [27] established a physical model with multiple combustors according to the Brayton cycle and also considered the rotation of hot gas in the turbine. The data-driven models use measurable parameters from the gas turbine's historical data to establish the EGT map, which does not require a clear understanding of the gas turbine's structure. Tarassenko et al. [28] proposed an EGT model based on a feed-forward neural network. According to the spatial distribution characteristics of thermocouples, the temperature of a thermocouple is estimated by using the temperatures of four thermocouples which are opposite the objective thermocouple in space. Bai et al. [29] proposed the concept of gas turbine normal pattern extraction for the first time, and based on nonlinear autoregressive with exogenous inputs network and prior knowledge fusion to extract the unchanged features of normal patterns from historical normal data and detect their changes for anomaly detection. Kenyon et al. [30] built an exhaust temperature influence model based on a neural network to eliminate the influence of changes in operating conditions on the detection results. Liu et al. [31] used the convolutional neural network to extract useful information from the exhaust temperature and eliminated the influence of the gas rotation effect and common mode interference on the detection. Yan [32], based on deep learning (DL), proposed a deep semi-supervised anomaly detection method, first extracting feature information from the EGT through DL, and then using a one-class classification to establish an EGT model and detect faults. Yildirim et al. [33], Ylmaz [15] and Song et al. [34] used multiple linear regression methods to establish the relationship between the EGT and measurable parameters. Zhu et al. [35] used a genetic algorithm (GA) to select the best input parameters firstly, and then established a mapping model between selected parameters and EGT using a support vector machine (SVM) with a linear kernel function. The second type of model-based method uses modeling parameters as detection factors and reflects the performance of the combustion system through changes in the detection factors. Liu et al. [36], based on gas turbine principle and Fisher discriminant analysis, established an EGT mechanism model and proposed a new detection factor, called the EGT vector. Medina et al. [27] used statistical techniques and wavelet analysis algorithms to detect changes in combustion system parameters.

It can be seen that there are many methods for combustion system fault detection. However, regardless of which method is more suitable, there is always a lack of comparative studies in this area. This paper will select several representative methods with different detection principles and compare their detection results on combustion system faults and provide relevant suggestions for further study. However, due to the fact faults may be 
coupled with many interference factors, the change rules of EGT are complicated. It is difficult to fully reveal the detection results of various methods under the influence of different interference factors by using the gas turbine data in actual operation. To this end, this paper is going to establish a gas turbine model that can be used in the study of combustion system fault detection, and then simulate the EGT when different interference factors are coupled with the combustion system fault, comparing the detection methods to point out the more suitable method for the combustion system fault detection. The actual operation data of a Taurus 70 gas turbine is then used to verify the comparison results, and the results are analyzed based on the mechanism. The methods compared in this paper are: the proposed method based on a Brayton cycle, GE's MARK VI gas turbine monitoring system, Siemens' TELEPERERM XP (TXP) monitoring system, Tarassenko's [28] proposed method based on EGT spatial characteristic, a data-driven EGT model in given in [35], and Liu's [36] proposed "EGT vector", etc.

The rest of this paper is organized as follows: Section 2 introduces the detection mechanism and detection principles of the selected six methods. In Section 3, a circumferential temperature distribution model for gas turbine combustion system fault detection is established and the model utilized to simulate the EGT data when various interference factors are coupled with faults. Section 4 introduces a comparison parameter, called sensitivity factor, and compares the detection results of the selected methods. The comparison results are verified by using the actual operation data of a gas turbine, and results are analyzed, then the key to sensitive detection is revealed in Section 5. Finally, Section 6 summarizes the whole paper and presents suggestions for the future development of gas turbine combustion system fault detection methods.

\section{Detection Mechanism and Methods}

In this section, the detection mechanisms of EGT distribution-based approaches are introduced. Based on the mechanism, many different detection methods are proposed and the mainstream methods' detection principles are introduced too.

\subsection{Detection Mechanism}

The three major components of a gas turbine are the compressor, burner and turbine. The compressor consumes work to compress air and then send it into burner where the fuel is combusted to produce a high-temperature and high-pressure gas. Then the hot gas enters the turbine to drive the rotor to do work, which drives the compressor, auxiliary equipment and generators to work. The burners of gas turbines are generally of the annular or ring tube type. The fuel enters the combustor through a number of fuel nozzles for combustion. Each combustor has the same structure and is evenly arranged along the circumferential direction. When a combustor faults, the temperature of gas in it will be affected. Therefore, if the outlet temperature of the combustor can be detected, the monitoring of the working status of combustors can be achieved. However, the combustor outlet temperature is too high and conventional thermocouples cannot work in that condition for a long time. At present, the general practice is to uniformly arrange temperature measurement thermocouples along the circumferential direction at the turbine outlet, and indirectly monitor the status of combustors, as shown in Figure 1.

Ideally, the hot gas temperature from different combustors is basically identical, so the corresponding gas path's temperature and the temperature measured by the thermocouples should be the same too. In practice, due to manufacturing and installation errors and slight differences in fuel supply, the readings of each thermocouple are not exactly the same, but the differences are very small. However, when the wall of combustor or transition section suffers cracks, deformation, ablation, carbon deposition, uneven fuel distribution or a jet angle deflection occurs, it will cause the outlet temperature of the faulty combustor to deviate from the temperature of other normal combustors, and such a deviation will pass through the turbine to the thermocouples. If the readings of one or several adjacent thermocouples are significantly different from those of other thermocouples, it indicates 
that the combustor corresponding to the thermocouple is faulty, as shown in Figure 2. That is to say, the fault detection of the combustion system is achieved based on the method of EGT distribution.

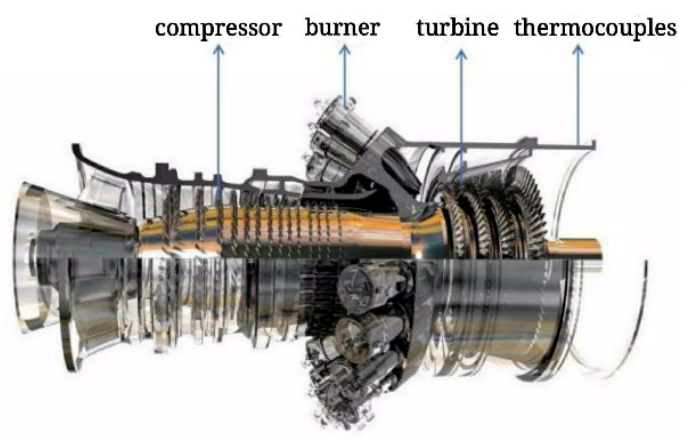

Figure 1. Schematic diagram of exhaust thermocouples.

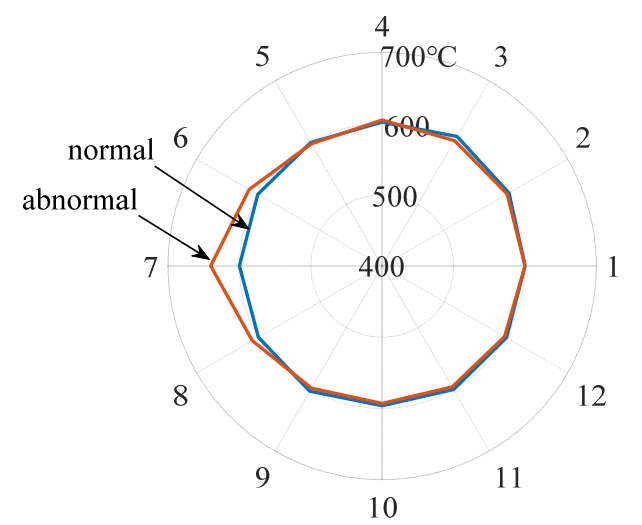

Figure 2. Influence of fault on EGT.

\subsection{Method Based on Brayton Cycle}

The operation of a gas turbine obeys the Brayton cycle, so the EGT can be calculated, using the measurable parameters, combined with Brayton cycle and the basic principles of the gas turbine [29]. Basseville [24] and Zhang [25] proposed a mechanism-based EGT model; Korczewski [26] established an EGT model based on the Brayton cycle. In [35], Zhu also deduced by Brayton cycle that the most relevant parameters with EGT are the compressor inlet temperature $T_{1}$ and fuel flow $q_{m f}$. In [29], Bai pointed out an EGT model based on Brayton cycle, which is a function of $q_{m f}, T_{1}$ and the compressor outlet pressure $P_{2}$. Considering that ambient pressure $P_{1}$ is easier to measure and it is the most relevant to $P_{2}$, the EGT model derived based on Brayton cycle can be summarized as the following equation:

$$
T_{4, i}=f_{i}\left(q_{m f}, T_{1}, P_{1}\right)
$$

This is an EGT distribution model based on thermodynamic principle, where $T_{4, i}$ represents the temperature at the $i$-th thermocouple. This also verifies the rationality of combustion system fault detection based on the EGT distribution. During the normal operation of the gas turbine, the mapping relationship between inputs and output is stable, so the temperature at each thermocouple is basically equal and stable. When a combustor fails, the temperature at the corresponding measuring point will deviate from the output of the model. When the residual exceeds the alarm threshold, it is considered that the combustion system has faulted. This is also the detection principle of the model-based method, as shown in Figure 3. In this paper, the EGT model based on the Brayton cycle is established by Extreme Learning Machine (ELM) with the compressor inlet temperature, compressor inlet pressure and fuel flow as inputs. 


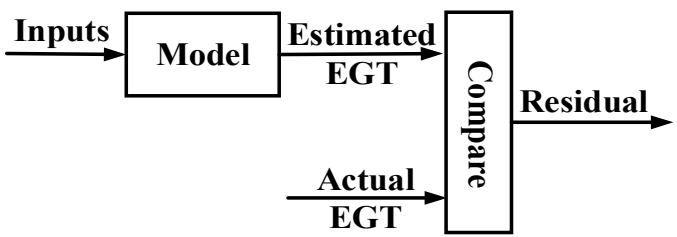

Figure 3. Schematic diagram of model-based fault detection method.

After verifying the rationality of fault detection based on EGT distribution, scholars began to utilize this feature to perform fault detection. The characteristic manifests that the greater the deviation of temperature between different measuring points, namely the higher the EGT dispersion, the higher the probability of combustion system faults. Therefore, the fault detection can also be realized by monitoring the EGT dispersion, and the US company GE and Germany's Siemens have developed relevant gas turbine monitoring systems to monitor combustion based on this principle.

\subsection{Gas Turbine Monitoring System Based on EGT Dispersion}

At present, the MARK VI system produced by GE and TELEPERERM XP (TXP) system produced by Siemens are widely used in gas turbine monitoring. They are based on the spread-based method, and monitor the EGT dispersion to detect faults.

\subsubsection{The Mark VI System Produced by GE}

Based on years of experience, GE defines a parameter $S$, allowable exhaust temperature dispersion, which is the function of compressor outlet temperature $T_{2}$ and the average EGT value $T_{4, a v g}$, as shown in Equation (2). The difference between the maximum EGT and the three minimum EGTs is used to measure the dispersion, as shown in Equation (3):

$$
\begin{gathered}
S=\left.\left(60+0.145 T_{4, a v g}-\left.0.08 T_{2}\right|_{50} ^{750}\right)\right|_{50} ^{170}+(100) \\
S_{1}=T_{4, \max }-T_{4, \min 1} \\
S_{2}=T_{4, \max }-T_{4, \min 2} \\
S_{3}=T_{4, \max }-T_{4, \min 3}
\end{gathered}
$$

The units of the above equations are ${ }^{\circ} \mathrm{F}$. The higher the ratio of the EGT dispersion to the allowable EGT dispersion, the greater the possibility of a fault. GE has also set up three empirical parameters $K_{1}, K_{2}$ and $K_{3}$, where generally $K_{1}=1.0, K_{2}=5.0$ and $K_{3}=0.8$. The discriminant principle is shown in Figure 4 [37].

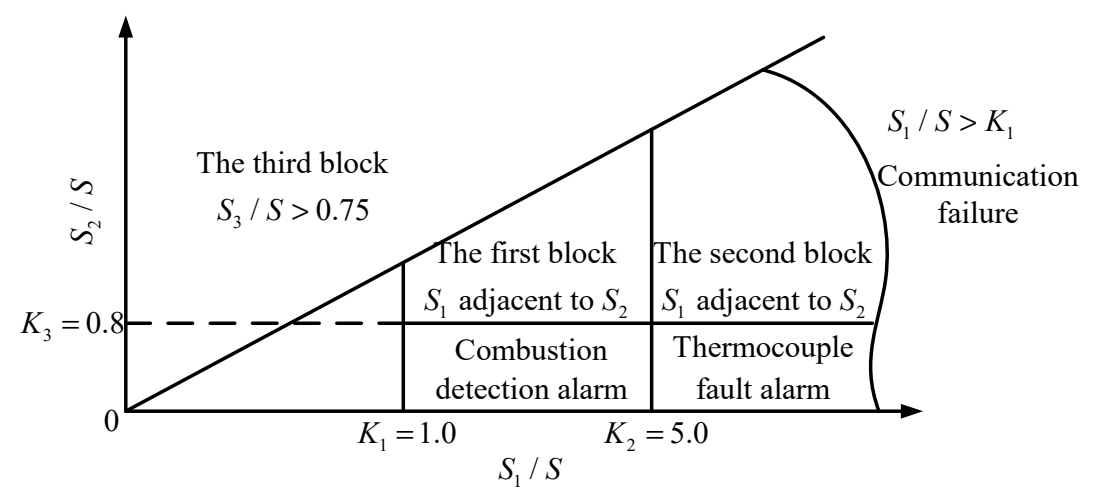

Figure 4. Discriminant diagram of combustion monitoring system in MARK VI system. 


\subsubsection{The TXP System Produced by Siemens}

The TXP monitoring system of Siemens also uses the dispersion of EGT for fault detection. It is based on the deviation between the EGT of each measuring point and the average EGT value. The protection logic is shown in Table 1 [21].

Table 1. EGT protection logic of the TELEPERX XP system.

\begin{tabular}{c} 
Name \\
Hot protection \\
$\begin{array}{c}\text { Comparing the average EGT value with the highest } \\
\text { temperature, if the deviation reaches the threshold, the } \\
\text { alarm will be given; if the protection action value is reached, } \\
\text { it will be blocked. }\end{array}$ \\
\hline High temperature protection $\quad \begin{array}{c}\text { The temperature of three or more measuring points is } \\
\text { higher than the protection action value, it will be blocked. }\end{array}$ \\
$\begin{array}{c}\text { Comparing the average EGT value with the lowest } \\
\text { temperature, if the deviations of two consecutive measuring } \\
\text { points are above the threshold, the alarm will be given; if } \\
\text { the deviations of three consecutive measuring points are } \\
\text { above the threshold, the gas turbine will maintain the load; } \\
\text { if the deviations of four or more consecutive measuring } \\
\text { points are above the threshold, it will be blocked. }\end{array}$ \\
\hline
\end{tabular}

In practical applications, the system also considers the influence of compressor outlet temperature, turbine rotational speed and other factors on the EGT, and corrects the EGT. The equation is as follows [21]:

$$
T_{4, \text { cor }}=T_{4, a c t}-\left(K_{1}+K_{3} \times T_{2}\right) \times T_{2}-K_{2} \times\left(1-N / N_{0}\right)
$$

where, $T_{4, \text { corr }}$ is the corrected EGT; $T_{4 a c t}$ is the measured valve; $N$ is the actual turbine rotational speed; $N_{0}$ is the rated turbine rotational speed; $K_{1}, K_{2}$ and $K_{3}$ are constants. When the deviation $r 1$ between a certain EGT and the average value exceeds the hot protection threshold, it will alarm. When the readings of two consecutive measuring points are lower than the average value, and the difference, $r 2$ and $r 3$, exceed the cold protection threshold, it will alarm too.

$$
\begin{gathered}
r 1=T_{4, \max }-T_{4, a v g} \\
r 2=T_{4, a v g}-T_{4, i} \\
r 3=T_{4, a v g}-T_{4, i+1}
\end{gathered}
$$

The MARK VI system utilizes a ratio and the TXP utilizes a difference, meanwhile, the threshold band of MARK VI and TXP system is fixed, and it will not change with the change of working conditions and environmental conditions. Different monitoring results will give warnings under the same threshold band. Therefore, many researchers have proposed detection methods that the threshold band will flexibly change with the monitoring results. The measurement results of different thermocouples have their own detection threshold band. The following methods are ones where the threshold band can flexibly change following the monitoring results.

\subsection{Method Based on EGT Spatial Characteristic}

The combustion system of a gas turbine is usually composed of several combustors with the same structure and uniformly arranged in the circumferential direction. Ideally, the combustion state of each combustor is basically identical, so the EGT distribution at the turbine outlet is basically uniform. Moreover, the probability of multiple combustors' faulting at the same time is very small, so the temperature of the thermocouple corresponding to the faulty combustor will be significantly different from that measured by others. However, due to the effect of blending and diffusion, the temperature of several adjacent thermocouples will also be affected. In other words, the temperature field of a 
combustor will affect several adjacent thermocouples; at the same time, the temperature of a thermocouple will also be affected by the state of multiple combustors, as shown in Figure 5. However, the temperature of several thermocouples opposite to this thermocouple corresponding to the faulty combustor in space is not affected by the faulty one. Therefore, in [28], Tarassenko used the spatial distribution characteristics of thermocouples and an artificial neural network (ANN) to establish the mapping between the EGT measurement point and the four opposite thermocouples, as shown in Figure 6, whereby the EGT model is established.

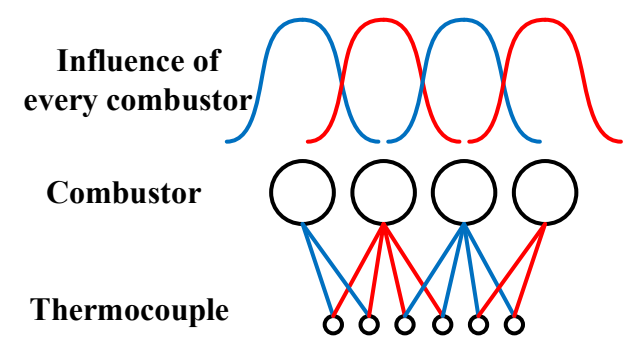

Figure 5. Influence of combustors on thermocouples.

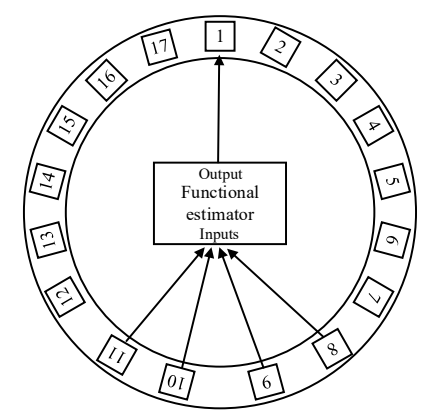

Figure 6. Relative positioning of inputs and output thermocouples.

In addition, the hot gas will swirl in the turbine with the rotation of the rotator, and the swirl angle has a nonlinear relationship with the turbine rotational speed $N$. Therefore, Tarassenko took $N$ as the fifth input parameter to estimate the EGT. The estimated model based on EGT spatial characteristic is as follows:

$$
\hat{T}_{4, i}=g\left(\vec{T}_{4}, N\right)
$$

where, $\hat{T}_{4, i}$ is the estimated temperature of the $i$-th thermocouple and $\vec{T}_{4}$ is the vector composed of the four opposite thermocouples' temperature. The nonlinear function $g$ is determined by an ANN with five inputs, one hidden unit and one output. In this paper, the single hidden layer feedforward neural network is achieved by using ELM, as shown in Figure 7.

This method belongs to model-based methods, which utilize the established model to calculate the estimated EGT according to the input parameters and compare them with the actual value to obtain a residual; the mechanism is shown in Figure 3. At the same time, this is also a method of artificially selecting input parameters, according to the EGT spatial distribution characteristics. In addition, GA, cross-correlation coefficient analysis, particle swarm optimization (PSO) and other algorithms are used to select the measurable parameters with the greatest correlation with EGT, and these parameters are used as inputs to estimate EGT. The EGT distribution models established in this way belong to the data-driven model class. 


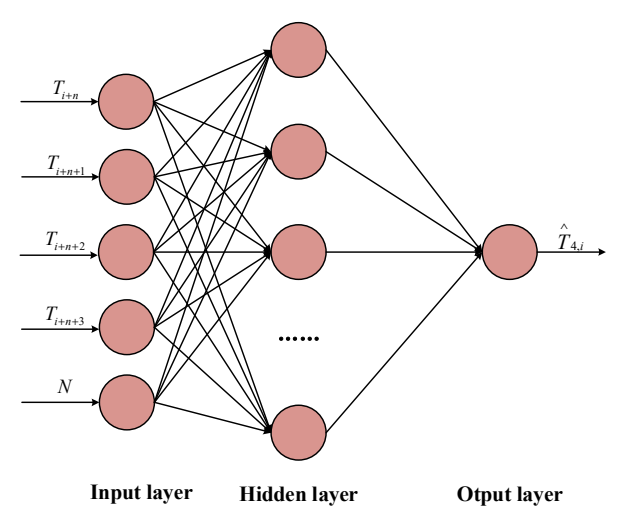

Figure 7. Structure of established ANN in this method.

\subsection{Method Based on Data-Driven Model}

Data-driven models use historical data of gas turbines and do not require accurate physical-mathematical models of the system. In recent years, the research of data-driven methods for gas turbine fault detection and diagnosis has attracted extensive attention [38-41]. In [35], through a mechanism analysis, Zhu extracted the frequent pattern model (FPM) of the EGT and found that the FPM would not change without the change of structure. When the structure changes, the actual EGT will deviate from the value of the FPM, which can be used as the basis for fault detection. Three parameters with the highest correlation with EGT are selected from hundreds of measurable parameters by using GA, which are average EGT value $T_{4, a v g}$, compressor inlet temperature $T_{1}$ and compressor outlet pressure $P_{2}$. Zhu compared the modeling results of the SVM using different kernel functions and found that the linear kernel function has the best performance. Therefore, the SVM with linear kernel function is used to describe the FPM, as shown in the following equation:

$$
T_{4, i}=f_{i}\left(T_{4, a v g}, T_{1}, P_{2}\right)
$$

The methods based on data-driven models also utilize the residual between the model outputs and the actual value for fault detection. In a model-based method, in addition to using the residuals for fault detection, there are also fault detection methods using modeling parameters.

\subsection{Method Based on EGT Vector}

In [36], Liu integrated the prior knowledge of gas turbine, established an EGT model, and used the modeling parameters to detect faults. The detection factor is called "EGT vector". The mechanism of fault detection using modeling parameters is as follows. The gas turbine system can be described as:

$$
y_{t}=F\left(\theta_{t}, X_{t}\right)+v_{t}
$$

where $y_{t}$ and the variable $X_{t}$ are measurable parameters, such as temperature, rotational speed, pressure, power, etc.; $v_{t}$ is the white noise independent of $X_{t} ; \theta_{t}$ is the performance parameter of the system. The performance parameter $\theta_{t}$ represents the inherent structural characteristics of system. If there is no fault, the system structure is basically unchanged, and accordingly the performance parameters will not change. When the fault occurs, the performance parameters change, which leads to the change of measurement parameters. Therefore, the change of performance parameters can be determined by observing the changes of measurable parameters to realize the fault detection of gas turbine. In [36], Liu utilized this feature to establish an EGT vector for fault detection of combustion system. Liu used the prior knowledge of gas turbines and combined the principles of thermodynamic to derive the EGT distribution model, as shown in Equation (9):

$$
T_{4, i}=\alpha_{i} T_{4, a v g}+\beta_{i} T_{1}+\sigma_{i} P_{2}+c_{i}
$$


This is a multiple linear regression model where $T_{4, i}$ is the estimated EGT of the $i$-th thermocouple. Since $\beta_{i} T_{1}+\sigma_{i} P_{2}+c_{i}$ is very small, only $\alpha_{i}$ is used as the detection factor and all $\alpha$ make up EGT vector. The EGT vector is the performance parameters of this system, and it is obtained by using the measurable parameters according to the least square method. When a certain $\alpha_{i}$ exceeds the threshold, it proves that the combustion system has malfunctioned.

It can be found that the input parameters of this model are the same as those of the data-driven model described in Section 2.5. It also shows that these three parameters are reasonable as the model inputs, but the difference is that Liu uses modeling parameters as detection factors, and the model is a multiple linear regression model; Zhu uses the residuals for fault detection. What's more, the established SVM model uses linear kernel function, but according to the principle of SVM and the architecture of SVM, as shown in Figure 8, the relationship between input parameters and output parameters is not a simple multiple linear relationships, on the contrary, this is a non-linear mapping.

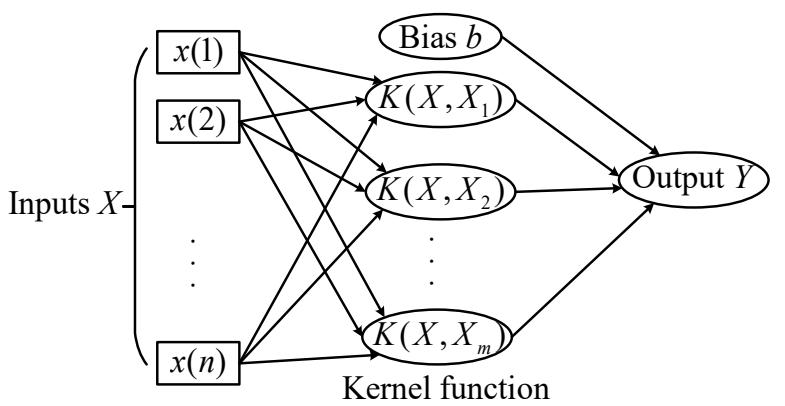

Figure 8. Architecture of SVM.

\section{Establish EGT Distribution Model for Comparative Study and Fault Simulation}

When using EGT distribution for fault detection, non-fault interference factors such as ambient conditions, operating conditions, hot gas rotation and mixing will influence the fault signal in the EGT profile, which makes the change rules of EGT intricate and complicated. It is difficult to fully reveal the detection effect of various methods under the influence of different interference factors by using the actual operational data of gas turbines. In this section, the modular modeling idea is adopted to establish a gas turbine model that can be used for combustion system fault detection research. After completing the establishment of the model, the EGT distribution under different conditions is simulated.

The traditional gas turbine model simplifies the combustion system into a whole, which reflects the overall characteristics and can only reflect the characteristics of the average EGT. In order to study the problem of gas turbine combustion system fault detection, which requires the gas turbine model to reflect the characteristics of EGT distribution, including the influence of combustion system fault on that. At the same time, the gas turbine model has to reflect the influence of various complex interference factors on the EGT distribution. The traditional gas turbine model obviously cannot meet the purpose of this paper. Therefore, the gas turbine model established in this section needs to have a multi-combustor burner structure, the fuel flow of each combustor can be controlled independently, and the inherent structural characteristics of different combustors can also be reflected. In order to cooperate with the multi-combustor burner module, it is necessary to establish a multi-channel turbine module to characterize the working process of the corresponding combustor outlet gas in turbine. Besides, it is necessary to reflect the mixing and rotating process of hot gas in turbine channel.

The gas turbine model for combustion system fault detection is improved on the basis of the traditional model. Its atmospheric parameter module, compressor module and shaft dynamic module are similar to those of traditional gas turbine model, specific methods refer to reference [42]. The main differences are the burner module, turbine module, mixing and rotating module. In this section, a model based on the GE-9FA gas turbine will be established. 


\subsection{Multi-Combustor Burner Module}

In order to characterize the state of each combustor and reflect the differences between them, the burner module cannot be simplified into a whole in the gas turbine model. The gas turbine model established in this section has 18 combustors. The modeling method of each combustor module is the same as that of single combustor in [42], and the parameters of each combustor module can be set separately. The difference is that the energy distribution coefficient $\mu_{i}$ of each combustor and the energy it can obtain $Q_{i}$ are introduced, as shown in Equation (10). The $\mu_{i}$ of each combustor are different, which can reflect its inherent structural information. The flow path of each combustor is relatively independent and the inlet and outlet parameters are also independent. The structure of the improved burner module is shown in Figure 9.

$$
\begin{gathered}
Q_{i}=\mu_{i} \cdot Q \\
\sum_{i=1}^{18} \mu_{i}=1
\end{gathered}
$$
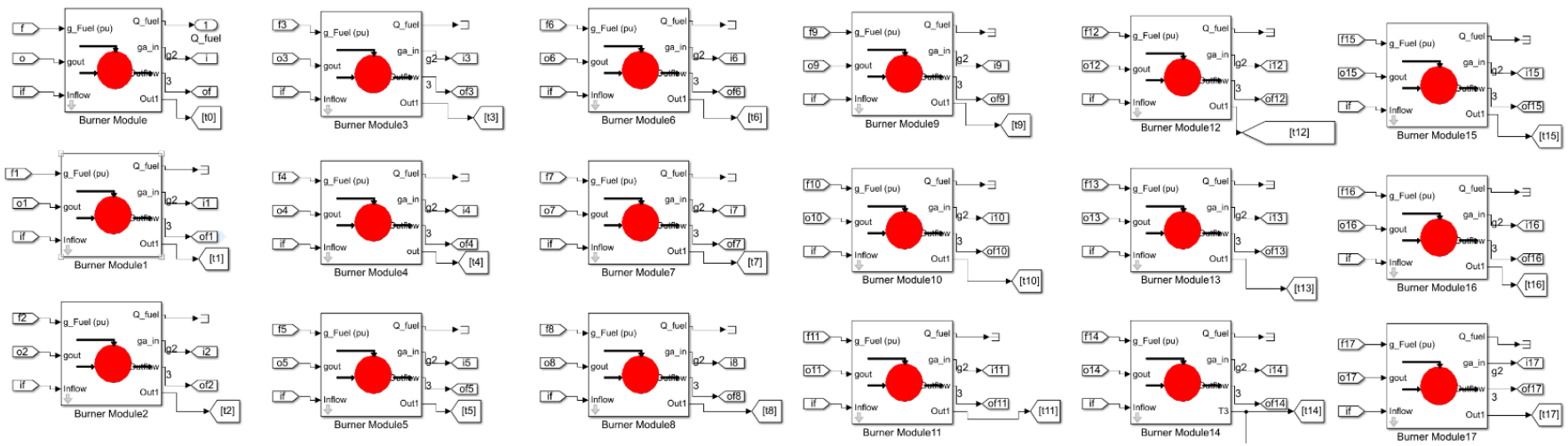

Figure 9. Burner module with multi-combustor.

\subsection{Multi-Channel Turbine Module}

Firstly, we assume that the hot gas from each combustor does not mix, and then expands to work in the turbine channel. In order to correspond with the burner module, it is necessary to establish the virtual turbine sub-module with the same number of combustors. Each virtual turbine sub-module is treated as a turbine channel to characterizes the working process of the corresponding combustor outlet hot gas in turbine. The sum of all virtual turbines' work is the total work of the gas turbine. The modeling process of each turbine channel is similar to that of traditional model in [42]. The established multi-channel turbine module is shown in Figure 10.
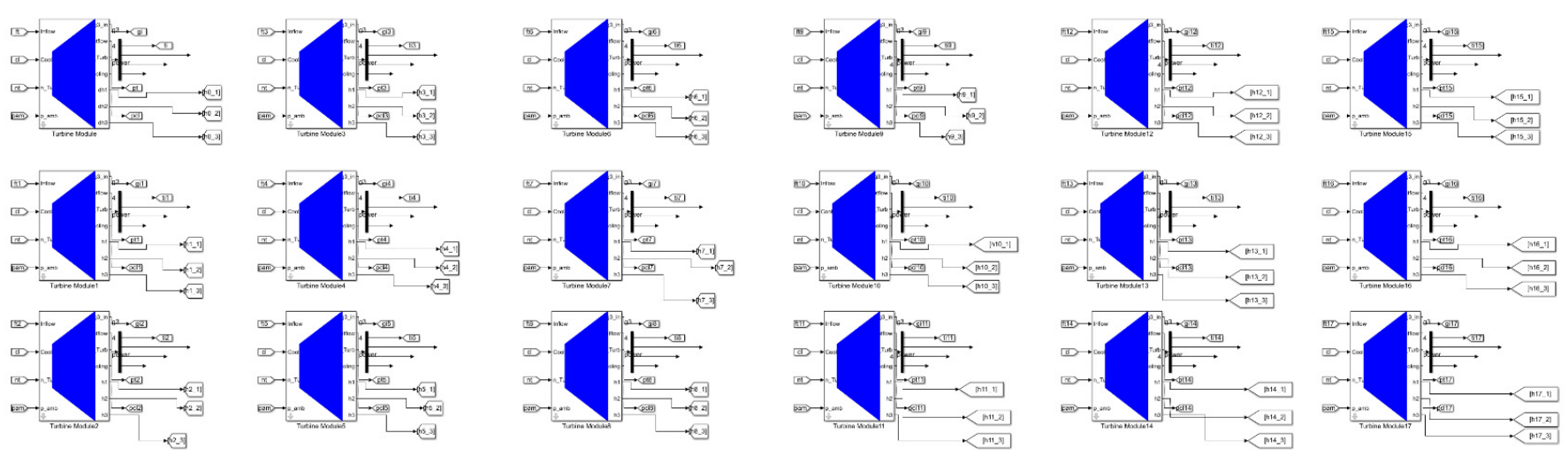

Figure 10. Multi-channel turbine module. 


\subsection{Mixing Module}

In Section 3.2, it is assumed that the gases from each combustor does not mix with each other. In fact, there is mixing between hot gases, and the mixing process can be divided into three stages. The first is the mixing of the hot gas in the transition between the burner outlet and the turbine inlet; the second is the mixing between the turbine stator and the blades; finally, there is mixing between the turbine outlet and the thermocouples. In this paper, these three mixing stages are combined into a total mixing module for modeling purposes.

The sensors for measuring the outlet temperature of gas turbines are evenly arranged in the circumferential direction at the turbine outlet, and the number of thermocouples is not necessarily the same as that of combustors. Taking the GE-9FA heavy-duty gas turbine as an example, it has 18 combustors and 31 thermocouples at the turbine outlet. As shown in Figure 11, the position of the \#18 combustor is defined as $0^{\circ}$ in this paper. At the same time, the influence rule of each combustor on temperature is that the center is the highest, and the farther away from the center, the lower the temperature. Therefore, the temperature at each position of the turbine outlet is the result of the common influence of multi-combustor. We refer to the solution in [27], assuming that the gas flows in a straight line in turbine, and the influence of each combustor on temperature is normally distributed, as shown in Figure 12.

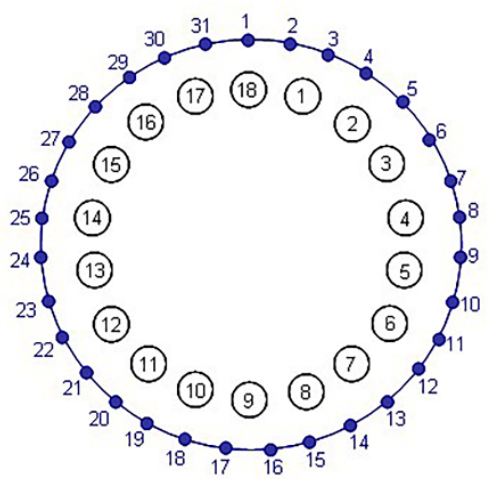

Figure 11. Combustors and thermocouples distribution of GE-9FA.

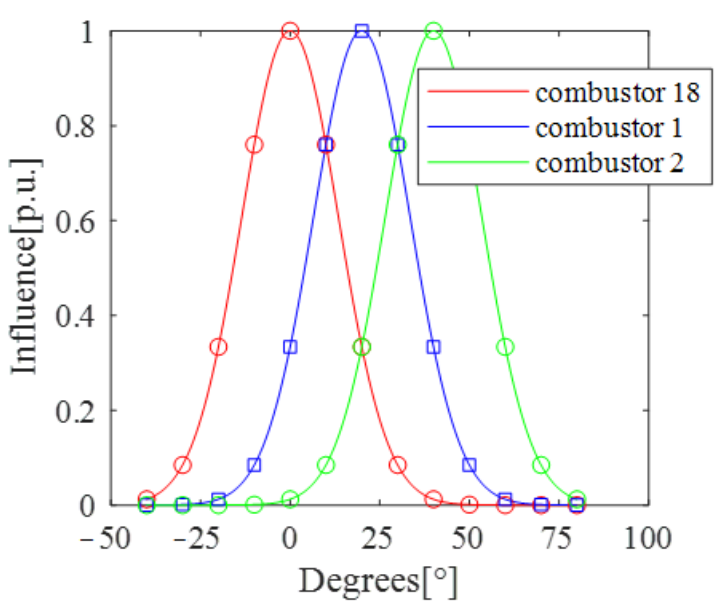

Figure 12. Influence of multi-combustor on burner outlet temperature.

Finally, the turbine outlet temperature distribution function is shown as follows:

$$
\begin{gathered}
T_{4}^{\text {profile }}(x)=\sum_{j=1}^{54} T_{4}^{j} \cdot f_{j}(x) \\
f_{j}(x)=A \cdot \exp \left(-\left(\frac{x-\alpha_{j}}{\sigma}\right)^{2}\right), x \in[2 \pi, 4 \pi]
\end{gathered}
$$


where $x$ is the position of a certain point at the turbine outlet; $f_{j}(x)$ is the influence function of the $j$-th combustor on exhaust temperature $\left(T_{4}\right) ; a_{j}$ is the position of the $j$-th combustor; $A$ and $\sigma$ are two constants; $T_{4}^{\text {profile }}$ is the EGT.

\subsection{Rotating Module}

After the hot gas from the combustor enters the turbine, it will rotate at a certain angle with the rotation of turbine. In this paper, according to the method mentioned in [43], the velocity triangle theory is used to calculate the swirl angle. The reference model in this paper is a GE-9FA, which has a three-stage turbine, so the swirl angle to be calculated is shown in Table 2, and the velocity triangle of hot gas in turbine is shown in Figure 13.

Table 2. Calculation of Swirl Angle.

\begin{tabular}{ccc}
\hline & Names & Symbols \\
\hline The first stage & $\begin{array}{c}\text { Swirl angle in the first stage stator } \\
\text { Swirl angle between the first stage blade and stator }\end{array}$ & $d_{1}^{1}$ \\
& $\begin{array}{l}d_{2}^{1} \\
d_{3}^{1}\end{array}$ & $d_{4}^{1}$ \\
\hline Swirl angle in the first stage blade & $d_{1}^{2}$ \\
\hline The second stage & Swirl angle between the first and the second stage & $d_{2}^{2}$ \\
& Swirl angle between the second stage blade and & $d_{3}^{2}$ \\
\hline The third stage & Swirl angle in the second stage blade & $d_{4}^{2}$ \\
\hline & Swirl angle between the second and the third stage & $d_{1}^{3}$ \\
& Swirl angle in the third stage stator & $d_{2}^{3}$ \\
& Swirl angle in the third stage blade & $d_{3}^{2}$ \\
& Swirl angle in the exhaust pipe & $d_{5}$ \\
\hline
\end{tabular}

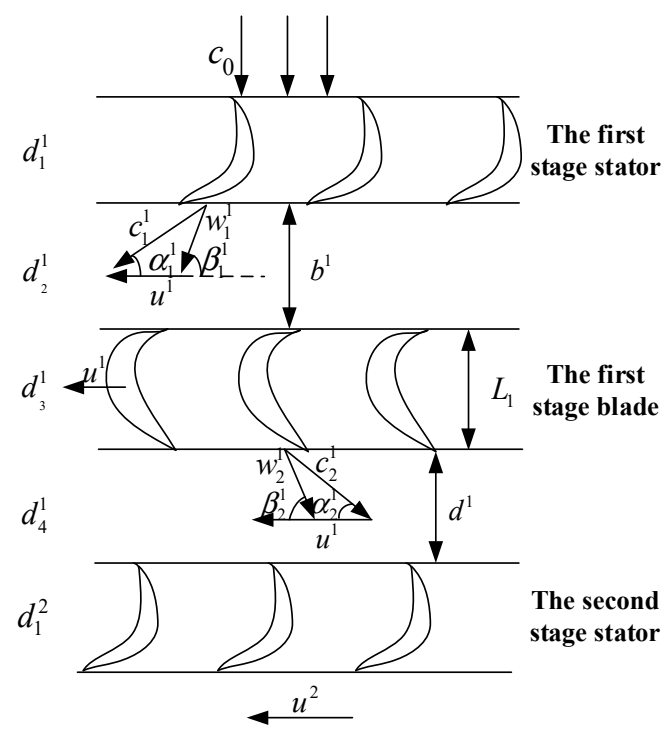

Figure 13. Calculation diagram of gas swirl angle based on velocity triangle.

Where, $c_{0}$ is the inlet velocity of the first stage stator; $c_{1}^{1}$ is the absolute velocity at the outlet of the first stage stator; $w_{1}^{1}$ is the relative velocity at the outlet of the first stage stator; $u^{1}$ is the circumferential velocity of the first stage blade; $b^{1}$ is the axial distance between the first stage stator and the first stage blade; $d^{1}$ is the axial distance between the first stage blade and the second stage stator; the velocity triangle of the second stage and the third 
stage turbine are similar to this. The swirl angles in Table 2 can be calculated by using the velocity triangle theory. The swirl angle $D$ is:

$$
D=\sum_{i=1}^{3}\left(d_{1}^{i}+d_{2}^{i}+d_{3}^{i}\right)+d_{4}^{1}+d_{4}^{2}+d_{5}
$$

In Section 3.3, it is assumed that the hot gas flows along a straight line in the turbine. Here, the swirl angle of hot gas in turbine is used to modify Equation (11), and the EGT distribution function considering mixing and rotating is obtained:

$$
\begin{gathered}
T_{4}^{\text {profile }}(x)=\sum_{j=1}^{54} T_{4}^{j} \cdot f_{j}^{\prime}(x) \\
f_{j}^{\prime}(x)=A \cdot \exp \left(-\left(\frac{x-\alpha_{j}-D}{\sigma}\right)^{2}\right), x \in[2 \pi, 4 \pi]
\end{gathered}
$$

\subsection{Overall Model}

The distribution model established in this paper is the same as the traditional gas turbine in the components of compressor module, ambient module and shaft dynamic module, etc., so it is not necessary to go into details here. The gas turbine circumferential temperature distribution model for combustion system fault detection based on the GE-9FA is shown in Figure 14 where $g$ is the flow; $P_{2}, P_{3}$ are the compressor outlet pressure and turbine inlet pressure, respectively; $T$ is the temperature; $n$ is the rotational speed; $P_{c}, P_{t}$, $P_{f}$ are the compressor power consumption, turbine power and load power, respectively. This model has a multi-combustor burner and a multi-channel turbine structure, can characterize the mixing and rotating effects of gas in turbine and can simulate the influence of many factors on EGT distribution, such as changes in ambient conditions, fuel flow fluctuations, fuel flow changes in each combustor, combustion efficiency changes, and component performance degradation.

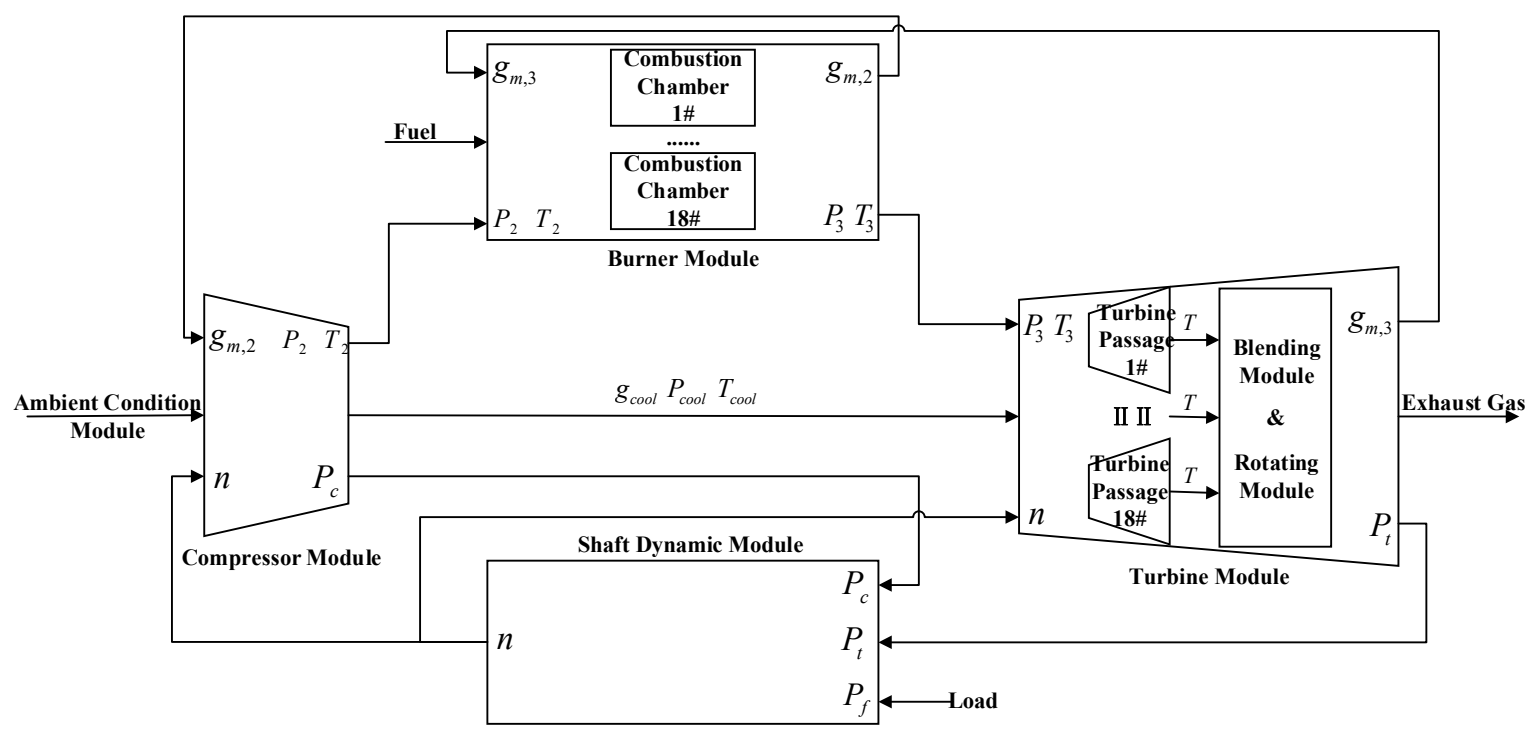

Figure 14. Circumferential temperature distribution model for combustion system fault detection.

\subsection{Fault Simulation}

Due to the fact that it is difficult for actual gas turbine operation data to fully reveal the influence of various interference factors on EGT, and the operational data of different interference factors coupled with combustion system fault is scarce, it is impossible to compare the detection effect of the various detection methods under different conditions. Therefore, it is necessary to use the model to simulate the EGT distribution when different interference factors 
are coupled with combustion system faults and systematically compare the detection effect of the selected methods by using simulated data. This paper will simulate the EGT distribution when the combustor fails, the coupling of faults and ambient temperature changes, the coupling of faults and atmospheric pressure changes, the coupling of faults and compressor performance degradation and the coupling of faults and fuel flow changes.

The first is the fault simulation of the combustion system. The typical faults of combustion systems include uneven fuel distribution, carbon deposition in fuel nozzles, jamming of nozzles and burning through of flame tube. Various fault factors will cause the fuel flow fluctuation or combustion efficiency fluctuation of the failure combustor, which will lead to the change of energy generated in the combustor, which is represented by the change of energy distribution coefficient $\left(\mu_{i}\right)$. Therefore, in the combustion system fault setting, various faults are represented as fluctuations in the $\mu_{i}$ of the combustor. In this paper, the $\mu_{i}$ of the faulty combustor is set to decrease slowly within $5000 \mathrm{~s}$ and then stop developing. As for changes in ambient temperature and atmospheric pressure, we set the corresponding changes in the ambient condition module. This paper sets the ambient temperature to rise by $10^{\circ} \mathrm{C}$ in $5000 \mathrm{~s}$ and the atmospheric pressure to drop by $100 \mathrm{~Pa}$ in $5000 \mathrm{~s}$, respectively, accompanied by the fault of a combustor. With the operation of the gas turbine, fouling and blade wear will occur in the compressor, which leads to a slight decrease in its efficiency. In the simulation, the compressor efficiency is set to drop by $5 \%$ within $5000 \mathrm{~s}$, accompanied by the fault of a combustor. During the operation of gas turbine, the load change will lead to the change of fuel flow. Here, we simulate the fuel flow increases by $5 \%$ in $5000 \mathrm{~s}$, accompanied by the combustor fault. Due to the space limitation, this section only shows the EGT of single fault and the EGT when the fault is coupled with ambient temperature increases, as shown in Figure 15. Among them, different colors represent different thermocouples. It can be seen that the \#27 and \#28 thermocouples are significantly affected by the faulty combustor.

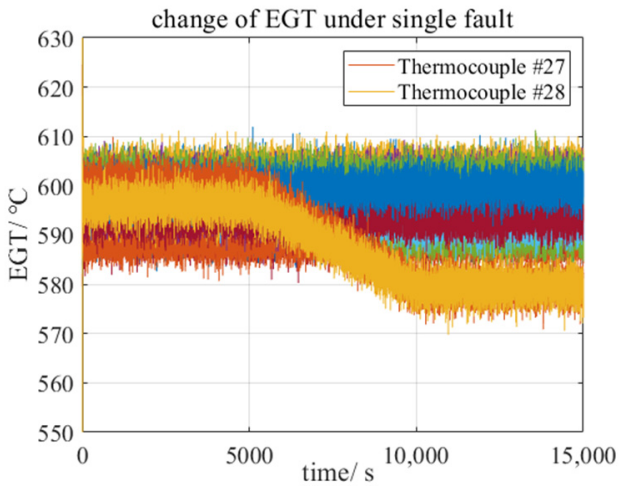

(a)

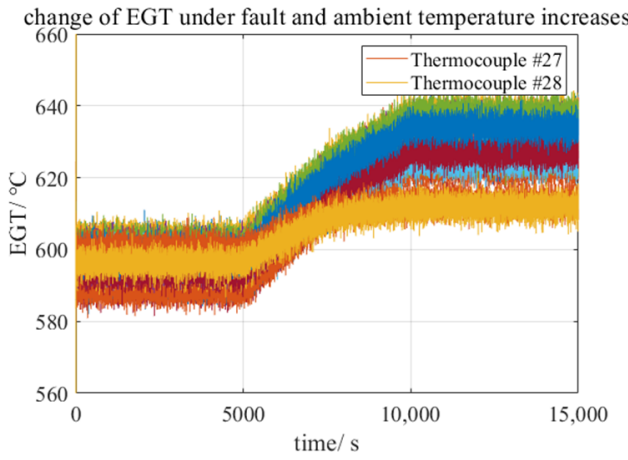

(b)

Figure 15. Change of EGT under different situation: (a) Single fault; (b) Fault couples with ambient temperature increases.

\section{Sensitivity Factor and Comparison}

In this section, we introduce how to compare the detection effects of each methods, and use the simulation data in Section 3 to test the detection effect of the selected methods.

\subsection{Sensitivity Factor}

In the Introduction, it was introduced that the EGT is affected by many interference factors, such as changes in ambient conditions, operating conditions, component performance degradation, fluctuations in fuel flow, rotation and the blending of hot gases. The faint information of temperature changes caused by combustion system faults will be submerged by these strong interference signals. From the perspective of pattern recognition, the samples of normal operation and abnormal operation can be regarded as different classes. As shown in Figure 16a, due to the influence of various interference factors, the 
intra-class distance is too large, the inter-class distance between the normal and abnormal class samples is too small. This causes the boundary between the normal and the abnormal class samples is fuzzy and it cannot be distinguished. This makes the sensitive detection of the combustion system faults more difficult and it is difficult for the monitoring system to detect the abnormality in time and give an alarm in an early stages of faults. However, if the fault detection method can suppress the influence of various non-fault interference factors, compress the intra-class distance, and expand the inter-class distance, reduce or even eliminate the class overlapping, as shown in Figure 16b, this can achieve the sensitive detection of early faults, detect anomalies in a timely way and send out alarms, which can effectively prevent the huge losses caused by the deterioration of the faults. The method that can achieve such a detection effect is a good method.

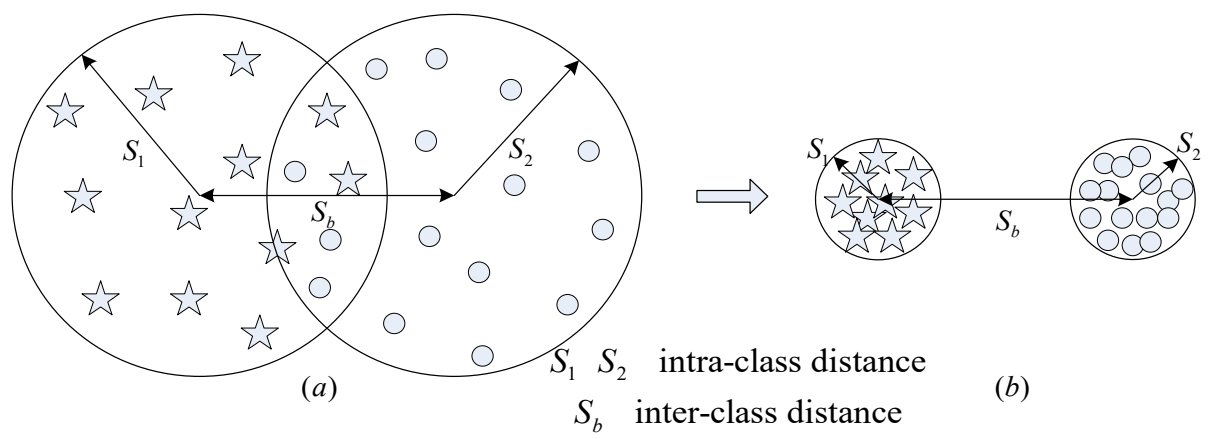

Figure 16. Intra-class and inter-class in pattern recognition.

Therefore, the sensitivity of the detection method can be measured by the ratio of inter-class distance to intra-class distance [44], as shown in Equation (14). The larger the ratio is, the easier the normal and abnormal samples can be distinguished, and the earlier the faults can be detected. However, the requirements of calculation intra-class distance and inter-class distance are extremely high to sample data, and the data measured by gas turbine monitoring system can hardly meet the requirements. Therefore, according to this idea, this paper defines a parameter, sensitivity factor $K$. It is the ratio of the deviation $\left(d_{1}\right)$ of the detection factor before and after fault to the threshold bandwidth $\left(d_{2}\right)$, as shown in Equation (15), the $d_{1}$ and $d_{2}$ are shown Detection result of the method based on EGT spatial characteristic in single fault.

$$
\begin{gathered}
K_{0}=\frac{S_{b}}{S_{1}} \\
K=\frac{d_{1}}{d_{2}}
\end{gathered}
$$

The deviation of the detection factor $\left(d_{1}\right)$ corresponds to the inter-class distance, and the width of the threshold band $\left(d_{2}\right)$ corresponds to the intra-class distance. The larger the $K$ value is, the more the detection method can suppress the influence of interference factors and the more sensitive it is on early faint faults. At the same time, the time $(t)$ required to detect fault is also taken as a comparative parameter. The shorter the time required, the more sensitive the detection method is too. After determining how to compare the test results, the follow-up contents are the comparative study of the selected methods in different situations.

\subsection{Single Fault}

Under this situation, the set operating state is that the gas turbine runs normally in the first $5000 \mathrm{~s}$, a soft fault occurs in a combustor at 5000-10,000 s, and the fault stops developing at $10,000 \mathrm{~s}$. Because the fault combustor has the greatest impact on the \#27 thermocouple, as shown in Figure 15, the detection results of some methods only show the monitoring of the \#27 thermocouple. The test results of the six selected methods are as follows. 


\subsubsection{Detection Result of GE's MARK VI Monitoring System}

This detection method utilizes the EGT dispersion for fault detection. The unit of temperature in the data is ${ }^{\circ} \mathrm{C}$ and after converting it to ${ }^{\circ} \mathrm{F}$, we calculate the allowable dispersion $S$ and maximum exhaust temperature dispersion $S_{1}$, and calculate their ratio. For a single fault, the detection result is shown in Figure 17. It can be seen from the result that the ratio of maximum temperature dispersion to allowable dispersion increased in the process, but it did not exceed the threshold, namely 1 . According to its alarm mechanism, shown in Figure 4, the monitoring system will not give an alarm in this process.

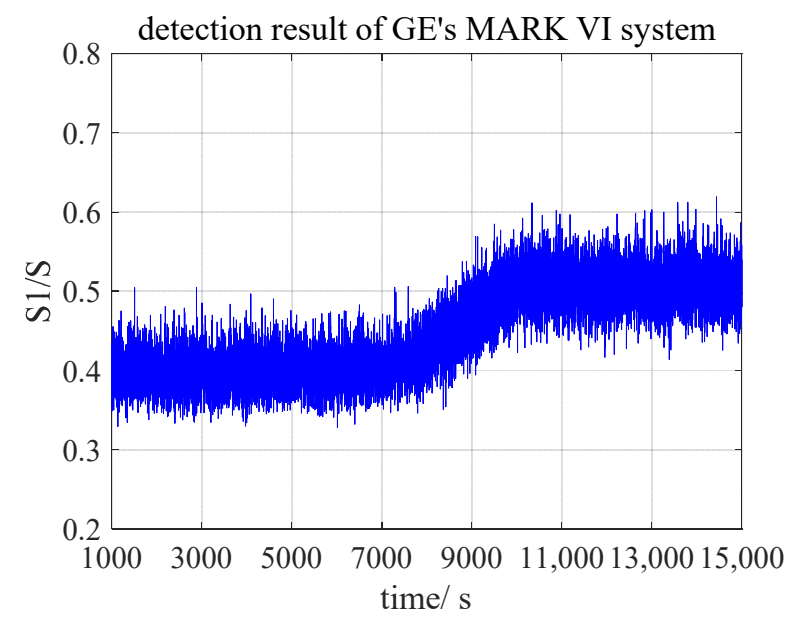

Figure 17. Detection result of MARK VI system in single fault.

\subsubsection{Detection Result of Siemens' TXP Monitoring System}

The hot protection of TXP monitoring system utilizes the deviation ( $r 1)$ between the maximum EGT and the average EGT for fault detection; while the cold protection is to monitor the value $(r 2, r 3)$ that the temperature of two consecutive measuring points lower than the average EGT. Referring to the protection temperature introduced in [45], $30{ }^{\circ} \mathrm{C}$ is selected as the hot protection deviation threshold, and $50^{\circ} \mathrm{C}$ is the cold protection threshold. That is, when the deviation exceeds the threshold value, the system will give an alarm. The result is shown in Figure 18. It can be seen from the detection result that the deviation of the cold protection has increased significantly, but the deviation has never exceeded the alarm threshold. According to its alarm mechanism, the system also did not issue an alarm during the entire process.
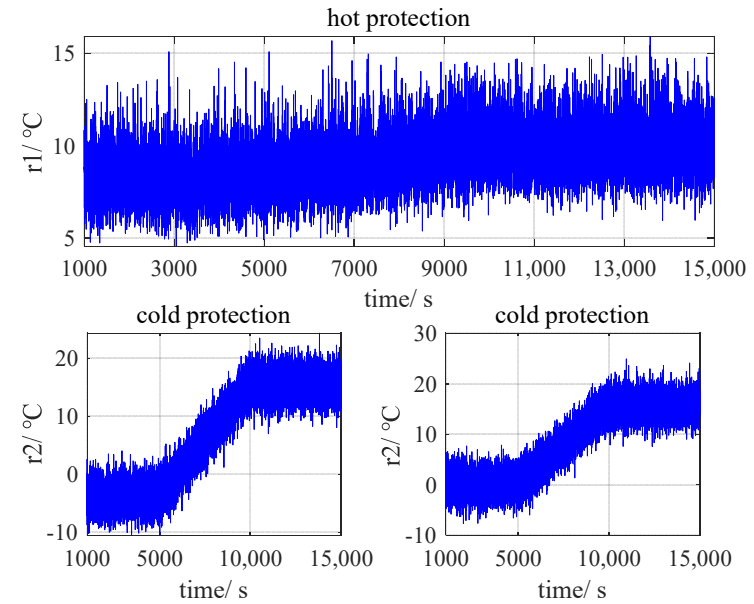

Figure 18. Detection result of TXP system in single fault. 


\subsubsection{Detection Result of the Method Based on EGT Spatial Characteristic}

This model-based method utilizes the residuals between the estimated and actual EGT for fault detection. Firstly, the data of the first $5000 \mathrm{~s}$ without fault is used to train model, and the detection threshold is determined according to Pauta criterion. This criterion is:

$$
\begin{gathered}
r_{i}=T_{4, i}-\hat{T}_{4, i} \\
\sigma=\sqrt{\frac{\sum_{i=1}^{n}\left(r_{i}-\frac{1}{n} \sum_{i=1}^{n} r_{i}\right)^{2}}{n-1}}
\end{gathered}
$$

where, $n$ is the number of samples in the training set. According to the Pauta criterion, as shown in Figure 19, set the detection threshold to $(-3 \sigma, 3 \sigma)$. When the residuals exceed this range, it is considered that a fault occurs.

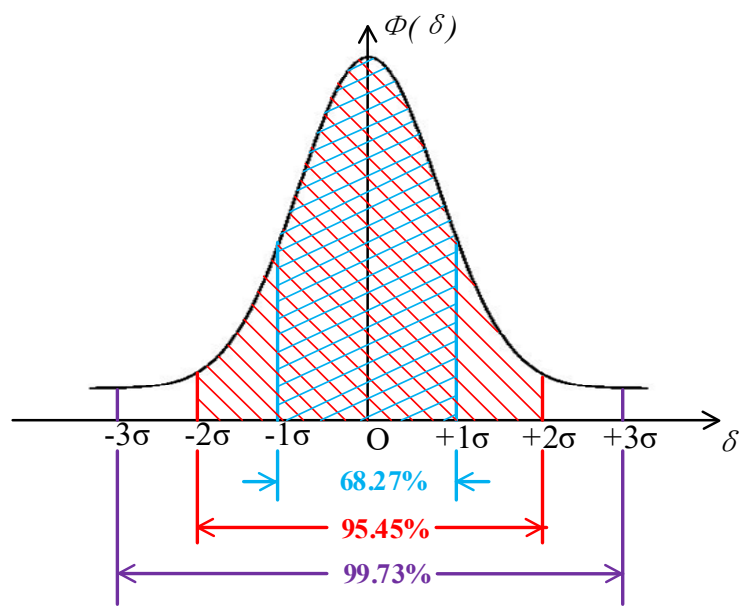

Figure 19. The diagram of Pauta criterion.

Since the temperature of \#27 thermocouple has the largest difference before and after the fault, it is modeled here. We select the temperature of \#10, \#11, \#12,\#13 thermocouples which are opposite to \#27 thermocouple and rotational speed as inputs, and the output is the estimated temperature of \#27 thermocouple. The unstable data of the first $50 \mathrm{~s}$ when the model is in the transition phase is removed. The residuals variation is shown in Figure 20. The detection threshold determined by the Pauta criterion is $(-8.253,8.253)$. The detection result of the model based on EGT spatial characteristics is shown in Figure 21. The blue line represents the change of residuals, and the black line is the threshold band.

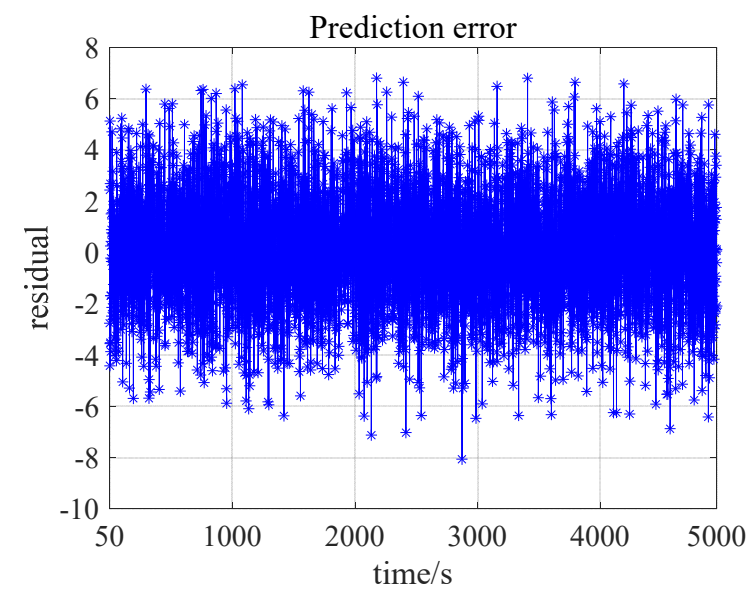

Figure 20. Prediction error. 


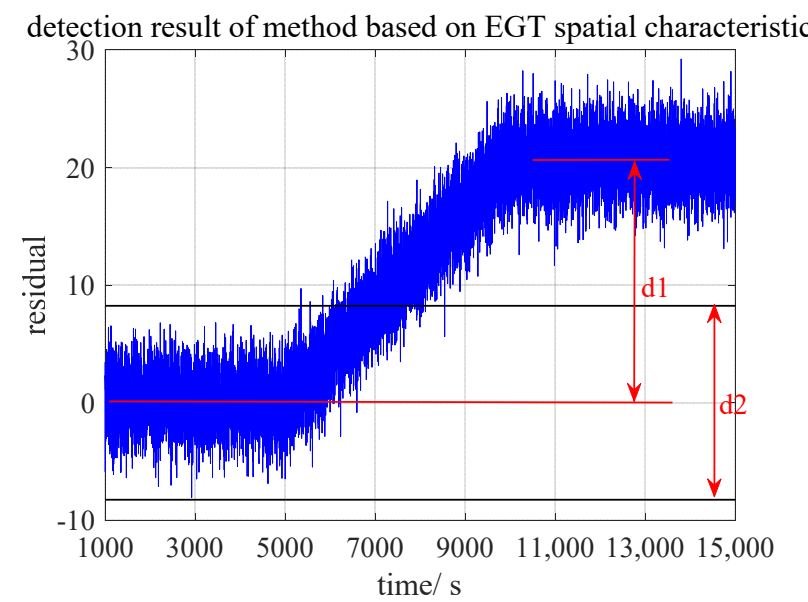

Figure 21. Detection result of the method based on EGT spatial characteristic in single fault.

It can be seen from the detection result that the method based on EGT spatial characteristic exceeds the threshold at about $2000 \mathrm{~s}$ after the fault occurs and the fault is detected. The sensitivity factor $K$ is 1.1414 .

\subsubsection{Detection Result of the Method Based on Data-Driven Model}

This method is also model-based, and utilizes the residuals for fault detection. Similarly, the data of the first $5000 \mathrm{~s}$ without fault is used to train model, and the detection threshold is determined by Pauta criterion. The threshold is $(-8.380,8.380)$, and the detection result is shown in Figure 22. It can be seen from the detection result that the residuals exceed the threshold at about $2200 \mathrm{~s}$ after the fault occurs. The sensitivity factor $K$ is 1.0332 .

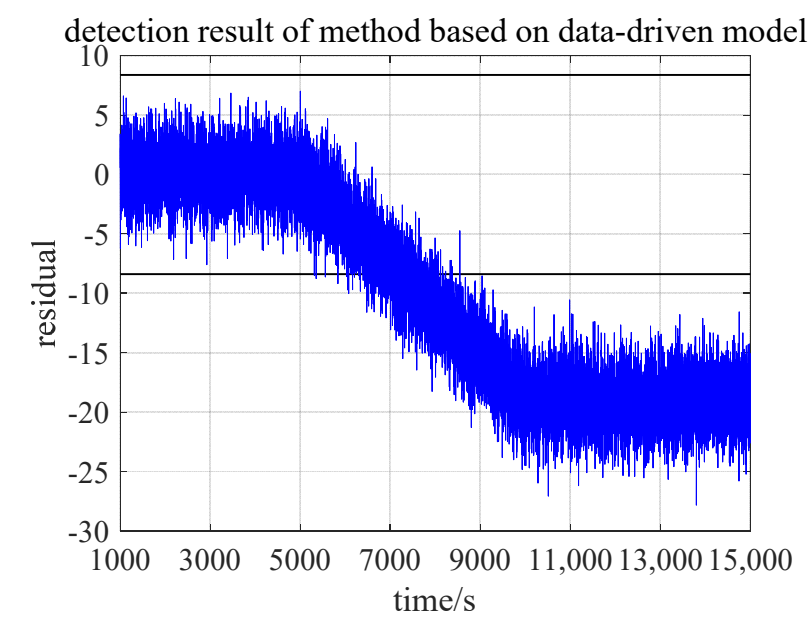

Figure 22. Detection result of the method based on data-driven model in single fault.

\subsubsection{Detection Result of the Method Based on EGT Vector}

The method based on EGT vector is a fault detection method using modeling parameters. In this section, firstly, the threshold of $\alpha_{2}$ is calculated by using the data of the first $5000 \mathrm{~s}$ without fault, and the threshold is $(0.9969,1.013)$, and the detection result is shown in Figure 23. 


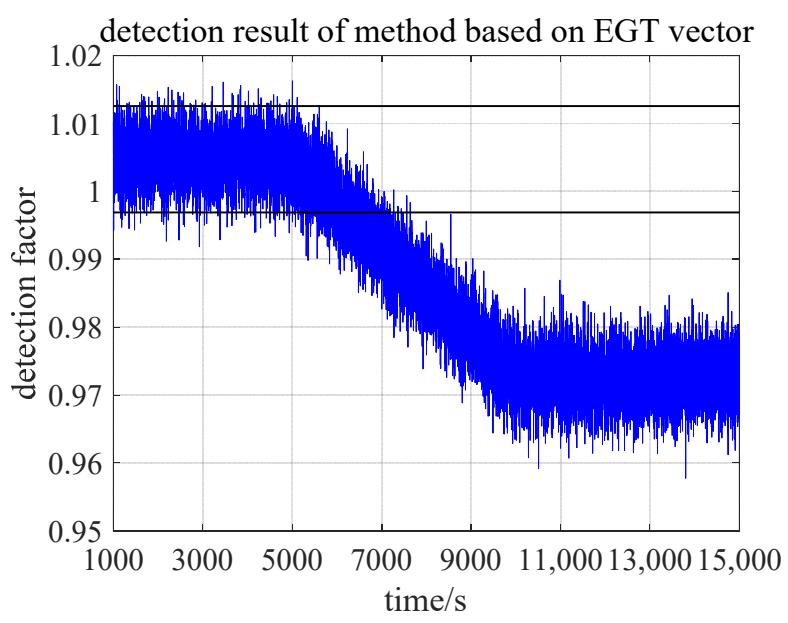

Figure 23. Detection result of the method based on EGT vector in single fault.

It can be seen from the detection result that the method based on EGT vector exceeds the threshold at about $1200 \mathrm{~s}$ after the fault occurs. The sensitivity factor $K$ is 1.4073 .

\subsubsection{Detection Result of the Method Based on Brayton Cycle}

The method based on the Brayton cycle in this paper is also a model-based method, which uses residuals for fault detection too. It is also achieved by ELM. It is trained by using the data of the first $5000 \mathrm{~s}$ without fault, and the threshold is $(-8.442,8.442)$, and the detection result is shown in Figure 24.

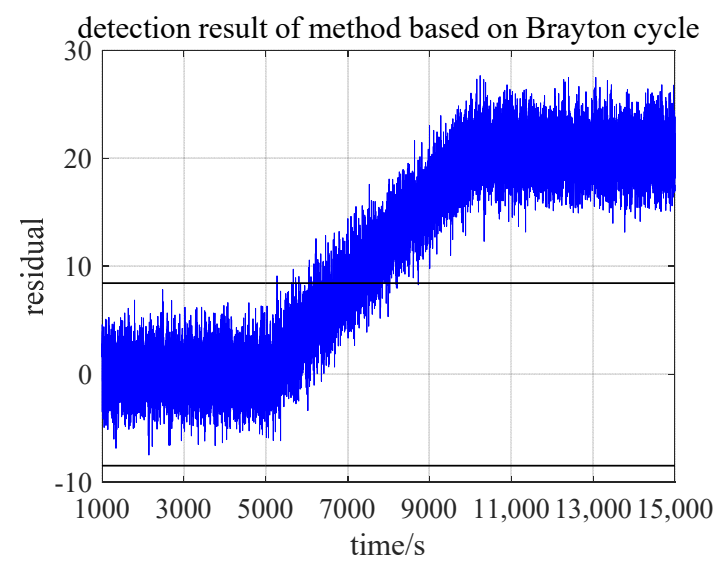

Figure 24. Detection result of the method based on Brayton cycle in single fault.

It can be seen from the detection result that the method based on Brayton cycle exceeds the threshold at about $2000 \mathrm{~s}$ after the fault occurs. The sensitivity factor $K$ is 1.1133 . Under the situation of single fault, the detection time $t$ and sensitivity factor $K$ of the method based on EGT vector are the best.

\subsection{Fault Couples with Ambient Temperature Increases}

As for the situation that fault is coupled with ambient temperature increases, the set operating state is that the gas turbine runs normally in the first $5000 \mathrm{~s}$. A soft fault occurs in the combustor at 5000-10,000 s and, at this time, the ambient temperature increases $10^{\circ} \mathrm{C}$ slowly. The fault and ambient temperature stop developing at 10,000 s. Due to space limitations, the detection results of those selected methods are not described in detail here. The detection results of MARK VI and TXP system are shown in Figure 25a,b. The monitoring ratio and deviation have increased obviously, however, according to the alarm mechanism, neither system will give an alarm for the coupling situation. The detection result of the method based 
on EGT spatial characteristics is shown in Figure 25c. The fault is detected at about $2000 \mathrm{~s}$ after the fault occurs, and the sensitivity factor $K$ is 0.6629 . The detection result of the method based on data-driven model is shown in Figure 25d, its detection factor always does not exceed the threshold, so it will not give an alarm, and the value of its sensitivity factor is not discussed. The detection results of the method based on EGT vector and Brayton cycle are shown in Figure 25e,f. The fault is detected at about $1500 \mathrm{~s}$ and $2000 \mathrm{~s}$ after fault occurs, the sensitivity factors $K$ are 1.1839 and 0.6195 , respectively.

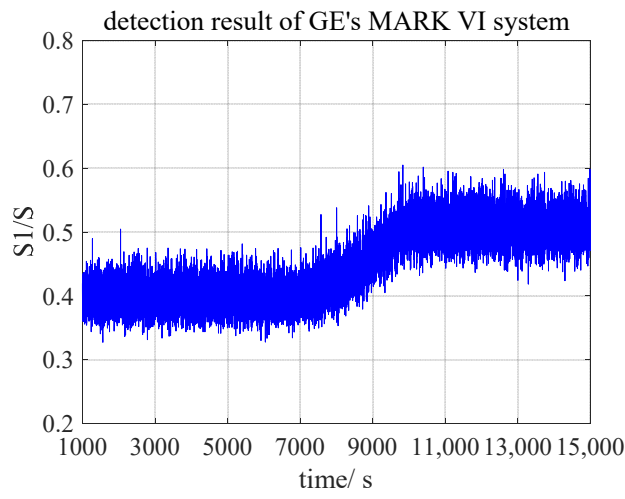

(a)

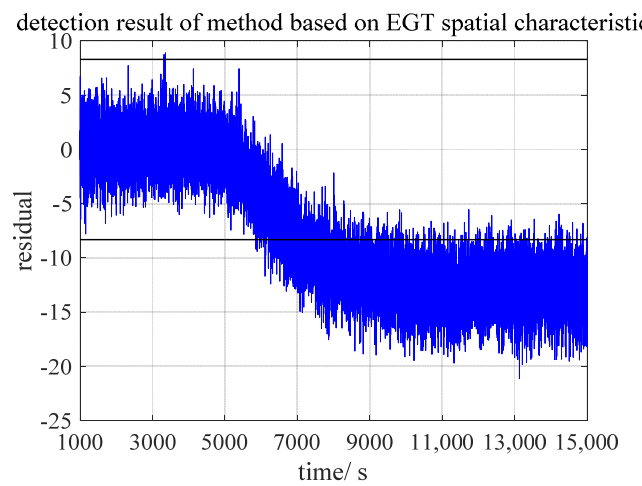

(c)

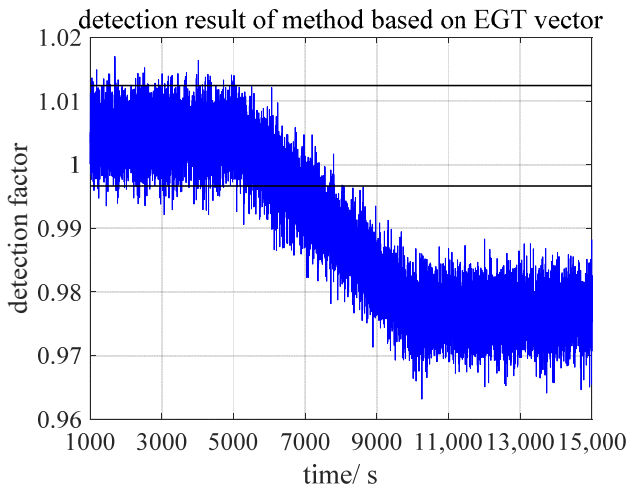

(e)

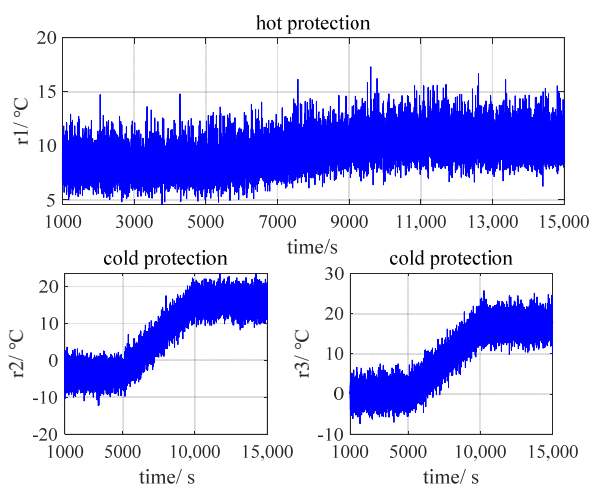

(b)

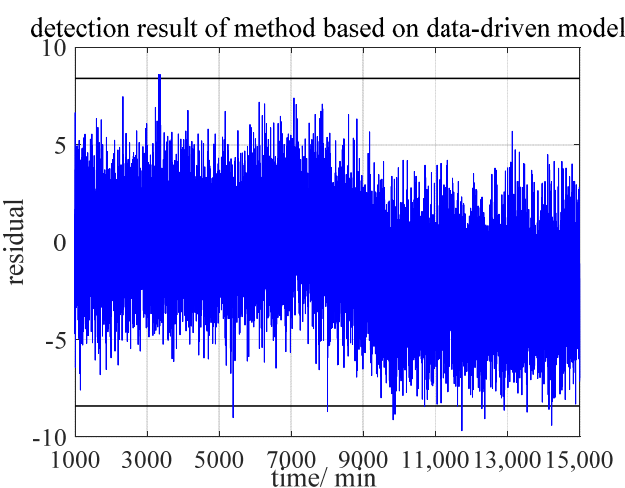

(d)

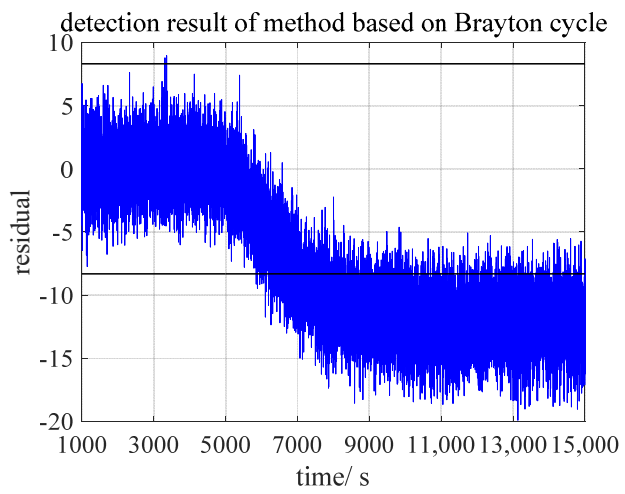

(f)

Figure 25. Detection results when fault couples with ambient temperature increases: (a) detection result of GE's MARK VI system; (b) detection result of Siemens' TXP system; (c) detection result of method based on EGT spatial characteristic; (d) detection result of method based on data-driven model; (e) detection result of method based on EGT vector; (f) detection result of method based on Brayton cycle. 
Similarly, from the comparison results, it can be seen that the fault detection method based on EGT vector still has the best detection effect, its detection time $t$ and sensitivity factor $K$ are the best, so its detection sensitivity for early fault is the highest.

\subsection{Results of Comparative Study Using Simulation Data}

This section also compares the detection results of these methods under the situation that fault couples with atmospheric pressure change, fault couples with compressor performance degradation and fault couples with fuel flow change. Due to space limitations, the detection results' figures of each method are not listed here. The time $t$ required of each detection method to detect the fault under different fault situation are shown in Table 3. The sensitivity factor $K$ of each method under different situations are shown in Table 4. Among them, the best results are bolded. For the case that the fault is not detected, denoted by "-" in the table, the value of the sensitivity factor $K$ is not discussed.

Table 3. The time required to detect fault.

\begin{tabular}{|c|c|c|c|c|c|c|}
\hline $\begin{array}{ll}\text { Faults } & \text { Methods } \\
\end{array}$ & MARK VI & TXP & $\begin{array}{c}\text { EGT } \\
\text { Spatial Characteristic }\end{array}$ & $\begin{array}{c}\text { Data-Driven } \\
\text { Model }\end{array}$ & $\begin{array}{c}\text { EGT } \\
\text { Vector }\end{array}$ & $\begin{array}{c}\text { Bryton } \\
\text { Cycle }\end{array}$ \\
\hline 1. Single fault & - & - & $2000 \mathrm{~s}$ & $2200 \mathrm{~s}$ & $1200 \mathrm{~s}$ & $2000 \mathrm{~s}$ \\
\hline $\begin{array}{l}\text { 2. Fault and ambient } \\
\text { temperature change }\end{array}$ & - & - & $2000 \mathrm{~s}$ & - & $1500 \mathrm{~s}$ & $2000 s$ \\
\hline $\begin{array}{l}\text { 3. Fault and atmospheric } \\
\text { pressure change }\end{array}$ & - & - & $2000 \mathrm{~s}$ & $2200 \mathrm{~s}$ & $1200 \mathrm{~s}$ & $2200 \mathrm{~s}$ \\
\hline 4. Fault and fuel flow change & - & - & - & $4500 \mathrm{~s}$ & $1000 \mathrm{~s}$ & $1450 \mathrm{~s}$ \\
\hline $\begin{array}{l}\text { 5. Fault and compressor } \\
\text { performance degradation }\end{array}$ & - & - & - & $2500 \mathrm{~s}$ & $1200 \mathrm{~s}$ & - \\
\hline
\end{tabular}

Table 4. Sensitivity factor $K$.

\begin{tabular}{|c|c|c|c|c|}
\hline Methods & EGT Spatial Characteristic & Data-Driven Model & EGT Vector & Bryton Cycle \\
\hline 1. Single fault & 1.1414 & 1.0332 & 1.4073 & 1.1133 \\
\hline 2. Fault and ambient temperature change & 0.6629 & - & 1.1839 & 0.6195 \\
\hline 3. Fault and atmospheric pressure change & 1.0687 & 1.0244 & 1.3494 & 1.0686 \\
\hline 4. Fault and fuel flow change & - & 0.3958 & 1.5181 & 1.1681 \\
\hline $\begin{array}{l}\text { 5. Fault and compressor performance } \\
\text { degradation }\end{array}$ & - & 0.9251 & 1.3896 & - \\
\hline
\end{tabular}

The indicators monitored by MARK VI and TXP system both increased after the fault occurs, but they did not exceed the alarm threshold, so no alarm will be sent out in the whole process. It can be seen from the detection results that the methods based on EGT spatial characteristic, based on data-driven model and based on Brayton cycle can detect the fault, but there are situations that fault cannot be detected.

It is analyzed in Section 4.1 that the key to early fault sensitive detection is to suppress the influence of interference factors on EGT distribution and extract stable information reflecting the combustion system fault from the complex coupled EGT signals. That is to say, the methods based on EGT spatial characteristics, based on a data-driven model and based on the Brayton cycle have poor suppression effects on some interference factors. At the same time, whether it is the time needed to detect the fault or the sensitivity factor $K$, the method based on EGT vector has the best detection effect under all simulated fault situations. Besides, from Tables 3 and 4, it can be found that the larger the sensitivity factor $K$ is, the shorter the time required for fault detection, this phenomenon is the same as the result analyzed in Section 4.1, which also shows that the sensitivity factor $K$ can represent the sensitivity of different methods for fault detection. Through the comparative study using simulation data, it can be seen that the method based on EGT vector has the best detection effect and the highest sensitivity to fault signals, and the fault signals can be extracted sensitively in the weak signs of the early fault. 


\section{Verification and Analysis}

This section will utilize actual gas turbine operating data to verify the results of comparative study using simulation data in the previous section, and then analyze the detection results from the mechanism.

\subsection{Verifying by Actual Data}

In this paper, the actual operating data comes from a single-spool Taurus70 gas turbine which has 14-stage compressor blades, 3-stage turbine blades and 12 combustors. The rated rotational speed is $15,200 \mathrm{r} / \mathrm{min}$ and the rated power is $6890 \mathrm{KW}$. The EGT is measured by 12 thermocouples evenly arranged in the circumferential direction at the turbine outlet. During the 23,052 min of normal operation, data is recorded every minute. The changes in EGT, ambient temperature, compressor outlet pressure and rotational speed are shown in Figure 26. According to the method mentioned in [46], the data of fault is constructed by normal data. The exhaust temperature of \#1 thermocouple is set to drop $10{ }^{\circ} \mathrm{C}$ slowly within 15,000 20,000 min, as shown in Figure 27.
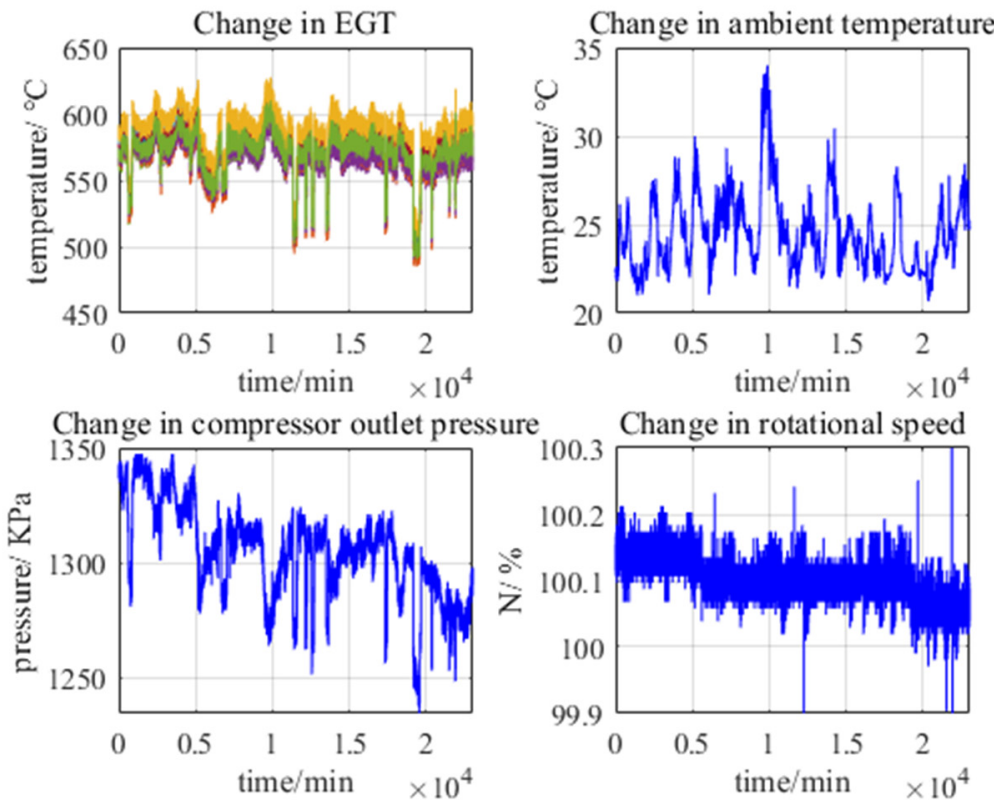

Figure 26. Operation date.

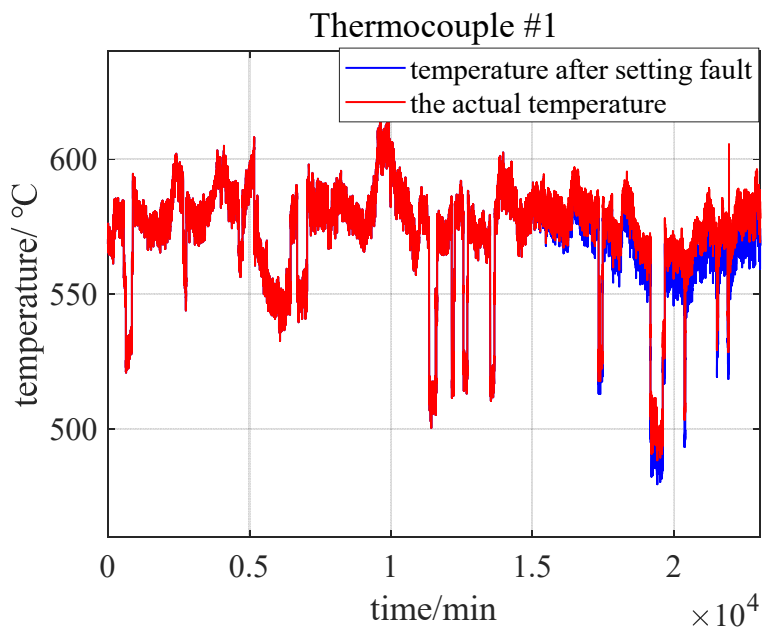

Figure 27. EGT of \#1 thermocouple before and after setting a fault. 
The MARK VI system and TXP system are spread-based methods and they utilize EGT dispersion for fault detection, the results of the two systems are shown in Figure 28a,b. It can be seen that the monitoring values of the two systems do not exceed the threshold, and there will be no alarm in the whole process, which is the same as the detection results of using the established temperature distribution model to simulate the early weak fault in Section 4.

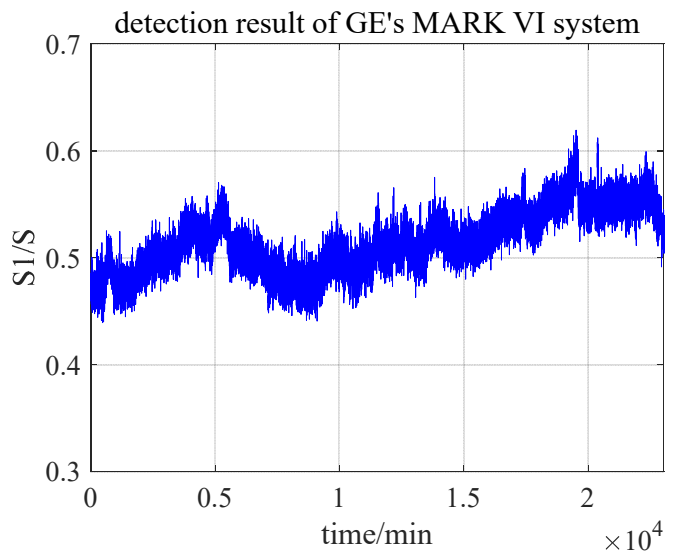

(a)

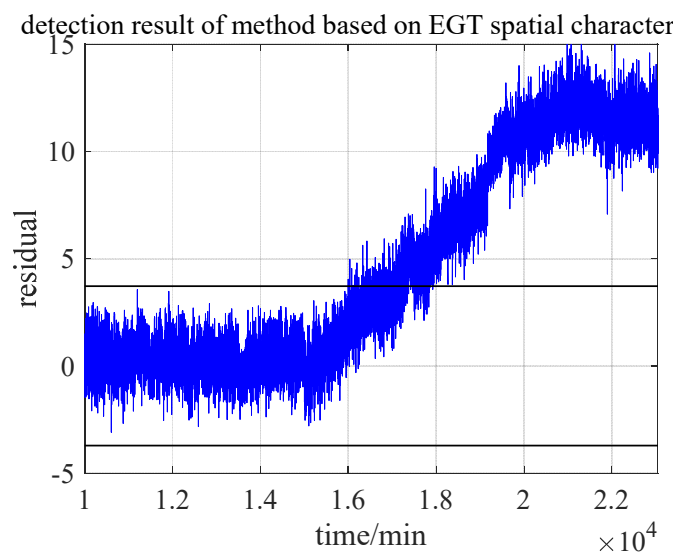

(c)

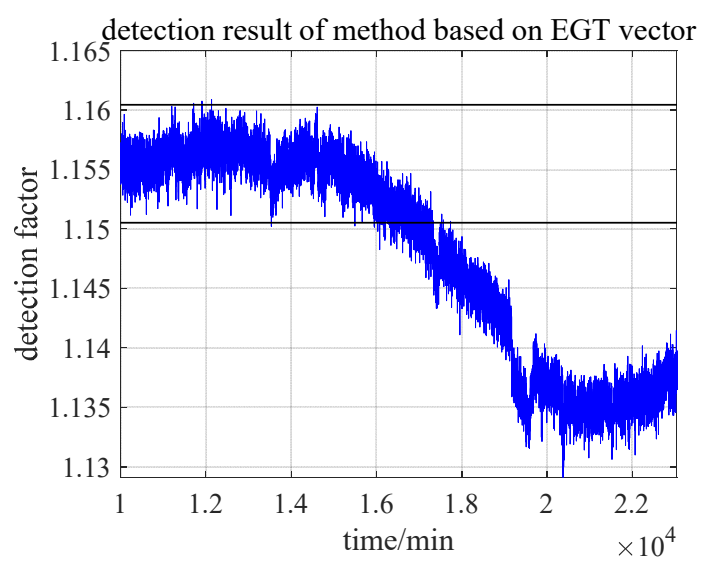

(e)

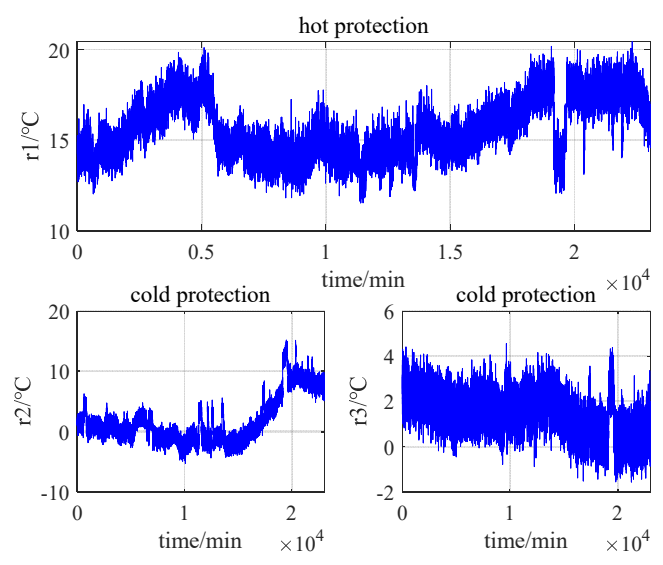

(b)

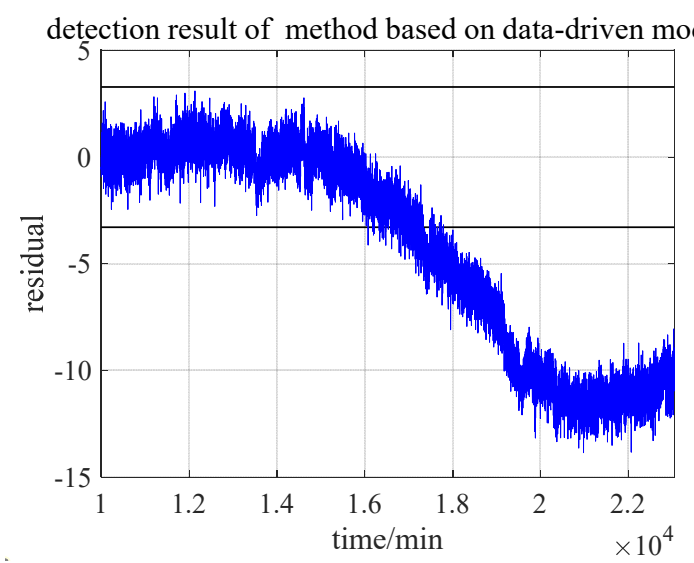

(d)

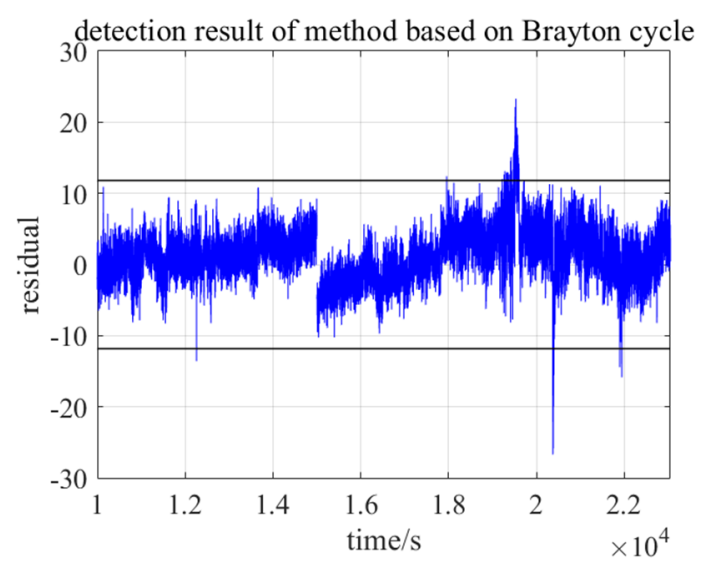

(f)

Figure 28. Detection results using actual data: (a) detection result of GE's MARK VI system; (b) detection result of Siemens' TXP system; (c) detection result of method based on EGT spatial characteristic; (d) detection result of method based on data-driven model; (e) detection result of method based on EGT vector; (f) detection result of method based on Brayton cycle. 
The methods based on EGT spatial characteristic, based on data-driven model, based on EGT vector and based on the Brayton cycle are all model-based methods. Their models are trained by the first 15,000 min data without fault set, and the detection thresholds are obtained respectively. The detection results of these four methods are shown in Figure 28. The time required for these four methods to detect fault and sensitivity factor $K$ are shown in Table 5.

Table 5. Detection results using actual data.

\begin{tabular}{ccccc}
\hline Method & \multirow{2}{*}{ ANN } & SVM & New Detection Factor & Brayton Cycle \\
Parameters & & & & \\
\cline { 1 - 4 } The time required to detect fault & $2000 \mathrm{~min}$ & $2000 \mathrm{~min}$ & $\mathbf{1 9 0 0} \mathbf{m i n}$ & - \\
Sensitivity factor $K$ & 1.4603 & 1.5839 & $\mathbf{1 . 9 8 8 7}$ & - \\
\hline
\end{tabular}

The established model based on the Brayton cycle cannot detect faults under this situation, while the others have good performance. It can be seen from the results that the method based on EGT vector has the best detection effect. The time required for fault detection is not significantly less than that of other methods, but its sensitivity factor $K$ is significantly greater than that of others. Therefore, its sensitivity of fault detection is obviously higher than that of others, which means that this method can detect the fault in an early stage, which is consistent with the results obtained by using simulation data. It also shows that the circumferential temperature distribution model of gas turbine for combustion system fault detection can reflect the actual operation of gas turbine, and the model is reasonable.

\subsection{Analysis}

This section will analyze the results from the mechanism, and the results of the comparative study are summarized to point out what kind of methods are more suitable for combustion system fault detection.

Firstly, as for MARK VI system, the reason why the alarm is not sent out may be that the temperature of the measuring point affected by the faulty combustor is not the highest or the three lowest, so the alarm mechanism of the combustion monitoring system will not be triggered. In addition, there are many factors that will cause the temperature dispersion between the thermocouples. For example, the manufacturing installation error will cause the inherent temperature difference to the EGT, and the variation of operating or environmental conditions will also cause the difference between the EGT. The allowable exhaust temperature dispersion $(S)$ defined by GE needs to suppress the influence of various interference factors on the EGT distribution and prevent a high false alarm rate, so it cannot be set too small. However, the influence of combustion system fault on the EGT dispersion is faint at an early stage. The signal of EGT change caused by fault factors is easily submerged by the signal of EGT change caused by interference factors. The combustion system has been damaged seriously once the alarm is generated. Similar to the MARK VI system, the TELEPEREM XP system is a gas turbine condition monitoring and protection system. In order to suppress the influence of interference factors on EGT and reduce the false alarm rate, the alarm threshold is set wide. The alarm will only be issued when the fault is serious. These systems can only protect the gas turbine, and they cannot identify and warn the faint signs in an early stages of a fault. Severe damage has occurred to the components by the time these systems give an alarm.

Secondly, as for the method based on EGT spatial characteristic, under the situations that simulated faults are coupled with different interference factors, this method can detect fault well in some cases while other cases cannot. Comparing these two kinds of cases, it can be found that the coupling condition of fault can be detected, such as fault coupling with ambient temperature increases and fault coupling with atmospheric pressure drops, the temperature change of the thermocouple corresponding to faulty combustor is obvious before and after fault. For the coupling condition that cannot detect fault, such as fault coupling with fuel flow increases and fault coupling with compressor performance 
degradation, the temperature of the thermocouple corresponding to the faulty combustor changes little before and after the fault. That is, if the interference causes the temperature of the thermocouple corresponding to the faulty combustor to change insignificantly before and after the fault, the malfunction cannot be detected even if the interference causes a significant change in the temperature of the four thermocouples spatially opposite to the thermocouple. It shows that using the temperature of the four thermocouples opposite to it in space and rotational speed as inputs can prevent the influence of the combustor faults on input parameters and estimate the temperature of the thermocouple, but artificially selecting the temperature of the thermocouples as inputs cannot suppress the influence of interference factors on the EGT. In the case of complex coupling, the fault cannot be detected.

Thirdly, comparing the method based on data-driven model with the method based on EGT vector, they both use the average EGT value, ambient temperature and compressor outlet pressure as the model inputs. The method based on data-driven model is to detect fault by using residuals of estimated temperature and actual temperature, the method based on EGT vector is to detect fault by using modeling parameters. In Section 4.1, it is analyzed that the interference factors cause the intra-class distance too large and the inter-class distance too small, namely, the sensitivity factor is too small, and the boundary between normal and abnormal samples is too blurry to distinguish. Therefore, it is necessary to suppress the influence of various interference factors, compress the intra-class distance, expand the inter-class distance, and reduce or even eliminate the class overlap. The detection effect of the method based on data-driven model is not as good as that of the method based on EGT vector. The reason why the latter is better than the former can be analyzed from the perspective of pattern recognition. If the EGT at each moment $\vec{T}_{4}=\left[T_{4,1}, T_{4,2}, \ldots, T_{4, n}\right]$ is regarded as a point in the high-dimensional sample space $X$, then each sample point can be projected into the new high-dimensional sample space by Equation (9), so the following equation can be obtained:

$$
\vec{\alpha}=w^{T} \vec{T}_{4}
$$

where $w^{\mathrm{T}}$ represents the projection direction and vector $\vec{\alpha}=\left[\alpha_{1}, \alpha_{2}, \ldots, \alpha_{n}\right]$ is a point in the new high-dimensional sample space $Y$. Through appropriate projection and transformation, the vector $\vec{\alpha}$ in the new sample space is used as the detection factor of early warning of combustion system fault to effectively compress the intra-class distance, which makes it easier to separate the normal samples from the abnormal samples. Under the premise of a low false alarm rate, the faults of combustion system can be detected as early as possible and the fault signal has higher sensitivity. This makes the sensitivity factor $K$ of the method based on EGT vector significantly larger than that of the method based on data-driven model. In addition, there is another reason. Various interference factors have strong common-mode characteristics on the EGT. Under the influence of these interference factors, the exhaust temperature changes significantly, but it increases or decreases synchronously in general trend. Monitoring the difference between the EGT is the core of combustion system fault detection. The effects of various interference factors on EGT are synchronous, and they also affect the average EGT value equally. Therefore, the average value can be used as the main characterization of the "mode" in the common-mode interference. Therefore, the average EGT can eliminate various common-mode interference, that is, suppress the influence of non-fault interference factors on fault detection. Moreover, the average value has a strong linear relationship with the temperature of each measuring point. Using the average value as an input parameter, and a linear model with the temperature of each measuring point can best characterize the EGT distribution. Both models use the average EGT as an input parameter, and it has been analyzed in Section 2.6 that although the kennel function used in SVM is linear, the relationship between the exhaust temperature and the average EGT value in this model is not linear, on the contrast, it is a non-linear model. Therefore, this will reduce the accuracy of the model and the sensitivity of detection, which 
also results in that the detection effect of the method based on data-driven model is not as good as that of the method based on EGT vector.

What's more, Miller [22] thought that the median EGT also contains the information of various interference factors, so a fault detection method based on the median EGT was proposed. In this paper, in order to obtain the most suitable method for fault detection and find the best parameters for suppressing interference factors, the average EGT in the method based on EGT vector is replaced by the median EGT, as shown in the following equation:

$$
T_{4, i}=\lambda_{i} T_{4, \text { median }}+\beta_{i} T_{1}+\sigma_{i} P_{2}+c_{i}
$$

where, $T_{4, \text { median }}$ is the median EGT, and the modeling parameter $\lambda_{1}$ is used for fault detection. The detection result of the fault constructed by the actual data is shown in Figure 29. It exceeds the threshold at about $2000 \mathrm{~min}$ after the fault occurs, and its sensitivity factor $K$ is 1.5348 . At the same time, in order to prevent the contingency of setting fault for only \#1 thermocouple, the exhaust temperature data of 12 thermocouples are installed soft fault respectively, and obtain 12 sets of fault data. The method based on EGT vector, respectively, with the average EGT as the input and with the median EGT is used as the input to detect the fault of the 12 groups of data, and the average sensitivity factor of the two methods are calculated respectively to make the comparison results universal. The results are shown in Table 6. It shows that the method using the average EGT as input has better performance and higher sensitivity to fault signal. And the average EGT is better than the median EGT in fault detection for suppressing interference factors.

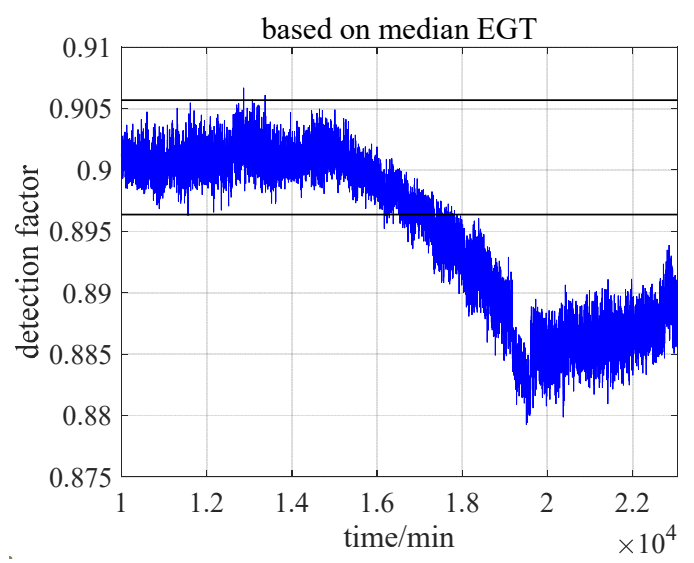

Figure 29. Detection result of method based on EGT vector taking median EGT as input.

Table 6. Sensitivity factor.

\begin{tabular}{ccc}
\hline & Average EGT & Median EGT \\
\hline \#1 Thermocouple fault & $\mathbf{1 . 9 8 8 7}$ & 1.5348 \\
Average value of 12 groups of faults & $\mathbf{1 . 5 4 7 6}$ & 1.4006 \\
\hline
\end{tabular}

Finally, the method based on Brayton cycle takes fuel flow, ambient temperature and atmospheric pressure as inputs and cannot detect fault which is constructed using actual operating data. Although the average EGT has a strong correlation with fuel flow, the interference factors, such as compressor performance degradation, cannot be characterized by the input parameters of the model and these non-fault factors cannot be suppressed. This also results in the method failing to detect fault when the simulated fault is coupled with compressor performance degradation. Therefore, replacing the average EGT with the fuel flow cannot suppress the influence of interference factors on the EGT and cannot achieve the sensitive detection for faults. 


\section{Conclusions}

At present, combustion system fault detection methods mainly utilize EGT distributions to extract fault signals based on temperature deviations. However, faults are not the only influencing factors. Various interference factors will affect the EGT profile and they can easily mask the temperature changes caused by faults. From the perspective of pattern recognition, the existence of interference factors makes the boundary between fault class and normal class indistinct and indistinguishable. Therefore, the key to combustion system fault detection is to suppress the influence of interference factors on EGT, extract fault signal from EGT, and improve the sensitivity of early faint symptom identification. For this reason, many researchers have proposed lots of methods. In this paper, they are divided into spread-based method and model-based method. However, there is a lack of comparative study on which method has the most obvious suppression effect on interference factors and which is the most sensitive to fault information. Therefore, six mainstream fault detection methods, based on different principles, are selected for comparative study in this paper, in an attempt to reveal the most suitable method for combustion system fault detection through comparative study and to find the parameters with the most obvious effect on the suppression of interference factors, so as to provide ideas for subsequent research.

This paper systematically studies the detection mechanism of the six selected detection methods, and gives a brief introduction. Before the comparative study, considering that the actual gas turbine operating data is difficult to fully reveal the EGT distribution under various interference conditions, it is impossible to systematically compare the detection effects of various methods under different conditions. To this end, this paper establishes a gas turbine circumferential temperature distribution model with a multi-combustor burner, multi-channel turbine, considering gas mixing and rotation. It can be used for combustion system fault detection research, and this model is used to simulate the EGT data under different fault situations. Besides, the sensitivity factor $K$ was defined by referring to the definitions of intra-class distance and inter-class distance, which can reflect the sensitivity of the detection method to fault signals and the suppression effect on interference factors. Then the simulation data are used to compare the selected methods. After the relevant results are obtained, the actual gas turbine operating data is used to construct a combustor fault situation, and the comparison in this case is used to verify the results obtained by simulation data. Finally, the comparison results are briefly analyzed. The results show that:

The GE MARK VI system and Siemens TELEEREM XP system use spread-based methods and utilize the EGT dispersion for fault detection. These methods are very intuitive, so they are widely used in industrial production, but, in order to prevent the influence of interference factors on the false alarm rate, a wide detection threshold is set, which makes them not sensitive enough to extract the weak signals in an early stages of faults, and the cannot trigger early warnings. When the system sends out an alarm, the components may have already been seriously damaged. In addition, the monitoring points may not include the thermocouples corresponding to the faulty combustor, so the detection effect of these systems is not good.

The model-based method can monitor the temperature change of each measuring point, and it is better than spread-based method. However, the detection results of these methods are uneven. Among the selected methods, the method based on EGT vector has the best performance. Comparing with the method based on EGT dispersion, we can know that all measurement points should be monitored during fault detection and methods suppressing interference factors should be found to improve detection sensitivity. Comparing with the method based on EGT spatial distribution characteristics, it can be seen that a good detection method should be based on the basic understanding of the fault mechanism of combustion system, and integrate the prior knowledge of gas turbine in the modeling process to select appropriate parameters to establish the model, so as to effectively suppress the influence of interference factors on EGT. Comparing with the method based on data-driven model selected in this paper, it is found that using modeling parameters as detection index can effectively compress the intra-class distance, which 
makes the abnormal samples more easily separated from normal samples. Meanwhile, the influence of interference factors on the EGT has a strong common-mode characteristic, and the average EGT can be used as the main characterization of the "mode". Using the average EGT can suppress all kinds of common-mode interference. And because there is a strong linear relationship between the exhaust temperature and the average EGT, the established model should be linear. Comparing with the method based on the Brayton cycle established in this paper and the method based on EGT vector taking median EGT as input, it can be seen that although the fuel flow has a strong correlation with average EGT, neither the fuel flow nor the median EGT can be used to replace the average EGT, which will affect the sensitivity of the detection method.

To sum up, in the study of gas turbine combustion system fault detection the average EGT value can effectively suppress the influence of interference factors on the exhaust temperature, and a linear model should be established between the temperature of each measuring point and the average EGT. In addition, using modeling parameters for fault detection can effectively improve the sensitivity, at the same time, it has a low false alarm rate, and can achieve the identification and early warning for weak faults signs.

Author Contributions: Conceptualization, Z.L. and J.L.; Methodology, M.B., L.Z.; Supervision, D.Y. and J.L. All authors have read and agreed to the published version of the manuscript.

Funding: This paper is funded by National Natural Science Foundation of China under Grant No. 51976042, National Science and Technology Major Project of China under Grant No. 2017-I-0007-0008, National Science and Technology Major Project of China under Grant No. 2017-V-0005-0055.

Acknowledgments: The authors would like to thank reviewers and editors for their valuable suggestions to refine this work.

Conflicts of Interest: The authors declare no conflict of interest.

\section{References}

1. Hongde, J.; Jing, R.; Xueying, L.; Qinxue, T. Status and Development Trend of the Heavy Duty Gas Turbine. Chin. J. Electr. Eng. 2014, 34, 5096-5102.

2. Mao, H.-J. Analysis of exhaust temperature monitor and protection function for gas turbine. Huadian Technol. 2009, $31,11-15$.

3. Sławiński, D.; Ziółkowski, P.; Badur, J. Thermal failure of a second rotor stage in heavy duty gas turbine. Eng. Fail. Anal. 2020, 115, 104672. [CrossRef]

4. Volponi, A.J. Gas Turbine Engine Health Management: Past, Present, and Future Trends. J. Eng. Gas Turbines Power 2014, $136,051201$. [CrossRef]

5. Tahan, M.; Tsoutsanis, E.; Muhammad, M.; Karim, Z.A. Performance-based health monitoring, diagnostics and prognostics for condition-based maintenance of gas turbines: A review. Appl. Energy 2017, 198, 122-144. [CrossRef]

6. Jiang, H.-N. The importance of exhaust temperature spread monitor during gas turbine operation. Gas Turbine Technol. 2007, 20, 13-16.

7. Liu, J.; Liu, J.; Yu, D. Anomaly Detection Method of Gas Turbine Combustion System Based on Exhaust Temperature Distribution Mode. In Proceedings of the Intelligent Power Plant Technology Development Seminar and Proceedings of 2013 Conference on Power Plant Automation, Shanghai, China, 12 October 2013; Available online: https:/ /kns.cnki.net/KCMS/detail/detail.aspx? dbcode $=$ CPFD\&filename=ZGDG201310002025 (accessed on 10 November 2020). (In Chinese).

8. Li, Y.G. Gas Turbine Performance and Health Status Estimation Using Adaptive Gas Path Analysis. J. Eng. Gas Turbines Power 2010, 132, 041701. [CrossRef]

9. Ge, J. Application of Endoscope in Gas Turbine Power Plant. Energy Environ. 2015, 2, 32-33. (In Chinese)

10. Sajben, M.; Peng, T.C.; Shaeffer, J.E. Evaluation of Experiments Using Electrostatic Probes to Detect. Imminent Failure of Jet Engine Gas-Path Components; Air Force Flight Dynamics Laboratory, Patterson Air Force Base: Wright, OH, USA, 1975.

11. Couch, R.; Robert, P. Detecting Abnormal Turbine Engine Deterioration Using Electrostatic Methods. J. Aircr. 1978, 15, 692-695. [CrossRef]

12. Powrie, H.; McNicholas, K. Gas Path Monitoring during Accelerated Mission Testing of a Demonstrator Engine. In Proceedings of the 33rd Joint Propulsion Conference and Exhibit, Seattle, WA, USA, 6-9 July 1997. [CrossRef]

13. Li, Y.; Zuo, H.; Liu, P. Gas path electrostatic monitoring of turbo-shaft engine: An exploratory experiment. Acta Aeronaut. Astronaut. Sin. 2010, 11, 2174-2181. (In Chinese)

14. Wen, Z.; Zuo, H.; Li, Y. Techniques and Experiments for Electrostatic Monitoring of Airway Particles. J. Aerosp. Dyn. 2008, 12, 2321-2326. (In Chinese)

15. Yilmaz, I. Evaluation of the relationship between exhaust gas temperature and operational parameters in CFM56-7B engines. Proc. Inst. Mech. Eng. Part G 2009, 223, 433-440. [CrossRef] 
16. Knowles, M. Gas turbine Temperature spread monitoring detection of combustion system deterioration. In Turbo Expo: Power for Land, Sea, and Air; The American Society of Mechanical Engineers: New York, NY, USA, 1994; Volume 78873, p. V005T17A002.

17. Zhu, L. Early Warning of High Temperature Components of Gas Turbine; Harbin Institute of Technology: Harbin, China, 2016. (In Chinese)

18. Hamilton, P.E.P.; Ha, D. Exhaust gas temperature capabilities now in system 1 software. Prod. Update 2005, 25, 88-89.

19. General Electric Company. Heavy Duty Gas Turbine Monitoring \& Protection; General Electric Company: Boston, MA, USA, 2015.

20. Johnson, D.; Gilbert, K.E.; Buckley, L.P. The SPEEDTRONIC Mark IV Control ${ }^{\mathrm{TM}}$, a distributed fault tolerant gas turbine control system. In Turbo Expo: Power for Land, Sea, and Air; The American Society of Mechanical Engineers: New York, NY, USA, 1983; Volume 79559, p. V005T13A007. [CrossRef]

21. Yu, H.; Xuewen, C. Control system Introduction for Siemens V94.3A gas turbine. Shanghai Electr. Power 2006, 19, 152-155. (In Chinese)

22. Miller, K.W.; Iasillo, R.J.; Lemmon, M.F. Method of Monitoring for Combustion Anomalies in a Gas Turbomachine and a Gas Turbomachine Including a Combustion Anomaly Detection System. U.S. Patent 9,790,834, 17 October 2017.

23. Gulen, S.C.; Griffin, P.R.; Paolucci, S. Real-Time On-Line Performance Diagnostics of Heavy-Duty Industrial Gas Turbines. J. Eng. Gas Turbines Power 2002, 124, 910-921. [CrossRef]

24. Basseville, M.; Benveniste, A.; Mathis, G.; Zhang, Q. Monitoring the Combustion Set of a Gas Turbine. IFAC Proc. Vol. 1994, 27, 375-380. [CrossRef]

25. Zhang, Q.; Basseville, M.; Benveniste, A. Early warning of slight changes in systems. Automation 1994, 30, 95-113. [CrossRef]

26. Korczewski, Z. Exhaust gas temperature measurements in diagnostic examination of naval gas turbine engines. Pol. Marit. Res. 2011, 18, 37-43. [CrossRef]

27. Medina, P.; Saez, D.; Roman, R. On Line Fault Detection and Isolation in Gas Turbine Combustion Chambers. In Proceedings of the ASME Turbo Expo, Berlin, Germany, 9-13 June 2008; pp. 315-324.

28. Tarassenko, L.; Nairac, A.; Townsend, N.; Buxton, I.; Cowley, P. Novelty detection for the identification of abnormalities. Int. J. Syst. Sci. 2000, 31, 1427-1439. [CrossRef]

29. Bai, M.; Liu, J.; Chai, J.; Zhao, X.; Yu, D. Anomaly detection of gas turbines based on normal pattern extraction. Appl. Therm. Eng. 2020, 166, 114664. [CrossRef]

30. Kenyon, A.D.; Catterson, V.M.; McArthur, S.D.J. Development of an intelligent system for detection of exhaust gas temperature anomalies in gas turbines. Insight-Non-Destr. Test. Cond. Monit. 2010, 52, 419-423. [CrossRef]

31. Liu, J.; Liu, J.; Yu, D.; Kang, M.; Yan, W.; Wang, Z.; Pecht, M.G. Fault Detection for Gas Turbine Hot Components Based on a Convolutional Neural Network. Energies 2018, 11, 2149. [CrossRef]

32. Yan, W. Detecting Gas Turbine Combustor Anomalies Using Semi-supervised Anomaly Detection with Deep Representation Learning. Cogn. Comput. 2020, 12, 398-411. [CrossRef]

33. Yildirim, M.T.; Kurt, B. Aircraft Gas Turbine Engine Health Monitoring System by Real Flight Data. Int. J. Aerosp. Eng. 2018, $2018,1-12$. [CrossRef]

34. Song, Y.X.; Zhang, K.X.; Shi, Y.S. Research on aeroengine performance parameters forecast based on multiple linear regression forecasting method. J. Aerosp. Power 2009, 24, 427-431.

35. Liu, J.; Zhu, L.; Ma, Y.; Liu, J.; Zhou, W.; Yu, D. Anomaly detection of hot components in gas turbine based on frequent pattern extraction. Sci. China Ser. E Technol. Sci. 2017, 61, 567-586. [CrossRef]

36. Liu, J.; Jiao, L.; Jie, W.; Zhongqi, W.; Yu, D. Early Fault Detection of Hot Components in Gas Turbines. J. Eng. Gas Turbines Power 2016, 139, 021201. [CrossRef]

37. Lifan, Y.; Yanlan, Y. Combustion failure analysis of 9F gas turbine. Power Gener. Equip. 2008, 22, 219-223. (In Chinese)

38. Pang, S.; Yang, X.; Zhang, X. Aero Engine Component Fault Diagnosis Using Multi-Hidden-Layer Extreme Learning Machine with Optimized Structure. Int. J. Aerosp. Eng. 2016, 2016, 1-11. [CrossRef]

39. Romessis, C.; Mathioudakis, K. Bayesian Network Approach for Gas Path Fault Diagnosis. J. Eng. Gas Turbines Power 2004, 128, 64-72. [CrossRef]

40. Liu, J.; Bai, M.; Jiang, N.; Yu, D. A novel measure of attribute significance with complexity weight. Appl. Soft Comput. $2019,82,105543$. [CrossRef]

41. Xu, Q.Y.; Meng, X.Y.; Han, X.J.; Meng, S. Gas Turbine Fault Diagnosis Based on Wavelet Neural Network. In Proceedings of the 2007 International Conference on Wavelet Analysis and Pattern Recognition, Beijing, China, 2-4 November 2007; IEEE: New York, NY, USA, 2017; Volume 2, pp. 738-741.

42. Wenjie, Z. Simulation Study of Single-Shaft Heavy-Duty Gas Turbine Based on Simulink; Tsinghua University: Beijing, China, 2011. (In Chinese)

43. Zhang, Q. Contribution à la Surveillance de Procédés Industriels. Ph.D. Thesis, University of Rennes I, Rennes, France, 1991.

44. Buja, A.; Swayne, D.F.; Littman, M.L.; Dean, N.; Hofmann, H.; Chen, L. Data Visualization With Multidimensional Scaling. J. Comput. Graph. Stat. 2008, 17, 444-472. [CrossRef] 
45. Yonggang, L. Analysis and countermeasures for exhaust deviation of Siemens SGT5-4000F(+) gas turbine. Intern. Combust. Engine Accessories 2018, 6, 44-46. (In Chinese)

46. Liu, J.; Kang, M.; Liu, J.; Wang, Z.; Yu, D.; Pecht, M.G. A Comparative Study on Anomaly Detection of the Combustion System in Gas Turbines. In Proceedings of the Society for Machinery Failure Prevention Technology Annual Conference 2017: 50 Years of Failure Prevention Technology Innovation, MFPT 2017, Virginia Beach, VA, USA, 16-18 May 2017; Available online: https: / / www.engineeringvillage.com/share/document.url?mid=cpx_bb6fc77160ff7e10bdM605410178163176\&database= cpx\&view=abstract (accessed on 10 November 2020). 